\title{
NOTAS ETNOFILOLÓGICAS SOBRE EL VOLUMEN 3169 DE LA BIBLIOTECA NACIONAL DE ESPAÑA. ALGUNOS ASPECTOS SOBRE LA ESCRITURA ANDINA COLONIAL'
}

\author{
ETHNOPHILOLOGICAL NOTES ON VOLUME 3169 OF THE BIBLIOTECA \\ NACIONAL DE ESPAÑA. SOME ASPECTS OF ANDEAN COLONIAL \\ WRITING
}

Paula Martínez Sagredoa

En este artículo se presenta evidencia etnofilológica acera de los distintos interventores en el proceso de conformación textual de los diversos documentos que forman parte del volumen 3169 de la Biblioteca Nacional de Madrid. Luego, se propone una metodología que permite vincular dichos documentos y reflexionar sobre algunas de las prácticas y dinámicas que subyacen a su materialidad y que redefinen instancias históricas de elaboración, tales como los talleres de escritura.

Palabras clave: Manuscrito Huarochirí, escritura colonial, escriba, volumen 3169, Andes.

The paper presents ethnophilological evidence of the individuals involved in creating the texts that make up Volume 3169, published by the National Library of Spain in Madrid. A methodology is proposed for linking these documents and for reflecting on some of the practices and dynamics that underlie their materiality and that redefine the historical contexts where the documents were made, such as writing workshops.

Keywords: Huarochiri manuscript, colonial writing, scribe, Volume 3169, Andes.

\section{INTRODUCCIÓN}

Uno de los primeros textos narrativos andinos -escritos casi íntegramente en quechua- es el Manuscrito de Huarochirí. ${ }^{2}$ Desde sus más tempranas ediciones, se ha vinculado la escritura del manuscrito con la figura del presbítero doctrinero Francisco de Ávila, quien en plena campaña de extirpación idolátrica se enfocó en la zona de Huarochirí en la predicación contra Pariacaca y Chaupiñamca, los wak'as más venerados de la región. ${ }^{3}$ Dicha campaña le permitió recabar una gran cantidad de tradiciones orales, que fueron recogidas muy probablemente en forma de cuestionario (Martínez 2011). Este documento ha recibido, sin duda alguna, gran atención por parte de numerosos estudiosos de las letras andinas, entre ellos José María Arguedas (1966), George Urioste (1983), Frank Salomon (1991), Alan Durston (2007) y Gérald Taylor $(1987,2008)$. Lejos de haberse clausurado el tema, con cada edición del manuscrito surgen nuevas interrogantes nacidas de la evidencia textual, etnohistórica o lingüística presentada. Así, por ejemplo, en la última edición, hecha por Taylor en 2008, el lingüista francés decide audazmente indicar como autor del Manuscrito de Huarochirí a Tomás, uno de los escribas que formó parte del proceso escriturario.

\footnotetext{
A Paula Martínez Sagredo, Universidad de Chile, Facultad de Filosofía y Humanidades, proyecto fondecyt Postdoctoral 3150110, Santiago, email: pmartinezsagredo@gmail.com
} 
La propuesta que se presenta aquí busca relevar los vínculos existentes entre los distintos procesos de creación de los manuscritos foliados en el volumen 3169 de la BNE y problematizarlos en cuanto a su manufactura y la incidencia de esta en el concepto de autor. Para ello, consideramos como una aproximación metodológica adecuada la sugerida por la etnofilología (Benozzo 2010; Martínez 2011, 2014) que, en principios generales, busca relevar el componente oral (entendido no necesariamente en su aspecto fonético-fonológico, sino más bien de tradición oral, formas narrativas orales, etc.), las dinámicas asociadas a él, las etapas de la conformación textual y, por sobre todo, entiende que la escritura es una práctica hegemonizante $y$, por tanto, pugnan en ella, como materialidad, las distintas fuerzas culturales y lingüísticas coyunturales. Es decir, contemplamos los testimonios escritos andinos coloniales como un producto material que necesariamente da cuenta de un complejo proceso de imposición idiomática (y con ella, evidentemente, una imposición cultural también) que manifiesta, entre otras cosas, paradigmas de dominación lingüística, desplazamientos idiomáticos, procesos e intentos de traducción y de mediación lingüística y cultural. Así, entonces, este artículo enfatiza ciertos rasgos materiales que nos permitirían reconstituir algunas de las dinámicas escriturarias de los manuscritos constituyentes del volumen 3169.

Veamos un ejemplo. Si se observa con detención, por ejemplo, las fojas $72 \mathrm{v}$ y $73 \mathrm{r}$ del volumen 3169 (figs. 1, 2 y 3) que corresponden al Manuscrito Huarochirí, podremos ver que en las anotaciones marginales se encuentran importantes datos sobre su proceso de conformación textual y sobre las distintas manos que aportaron a su escritura. Las transcripciones de ambos detalles son las siguientes:
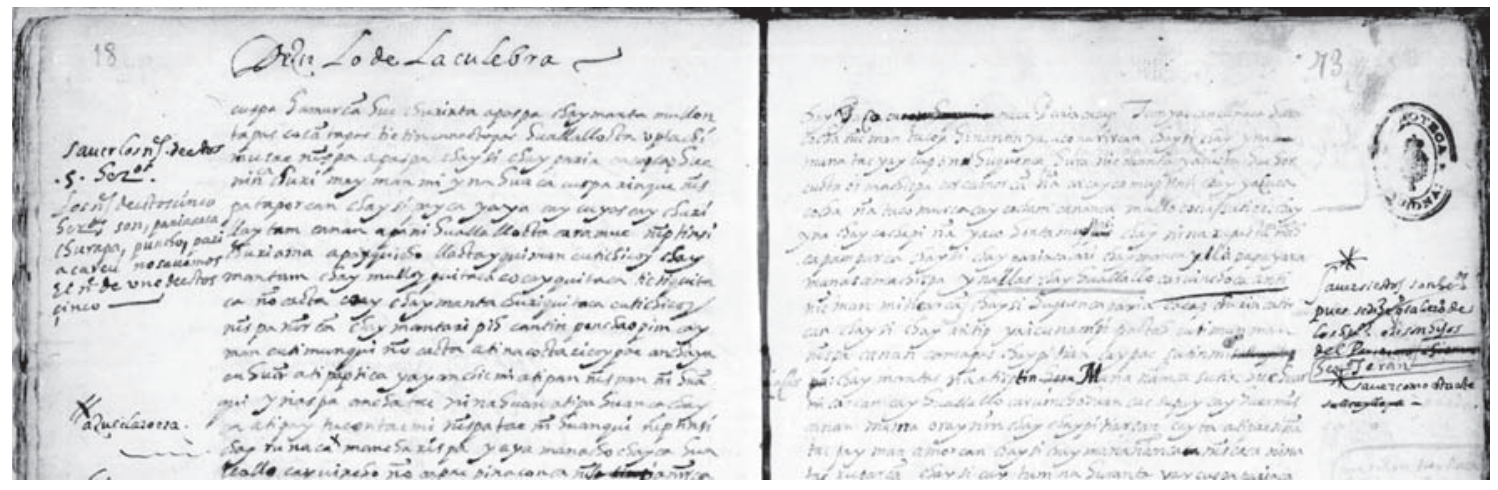

Figura 1. Fojas 72 v y 73 r. Figure 1. Folios $72 v$ and $73 r$.

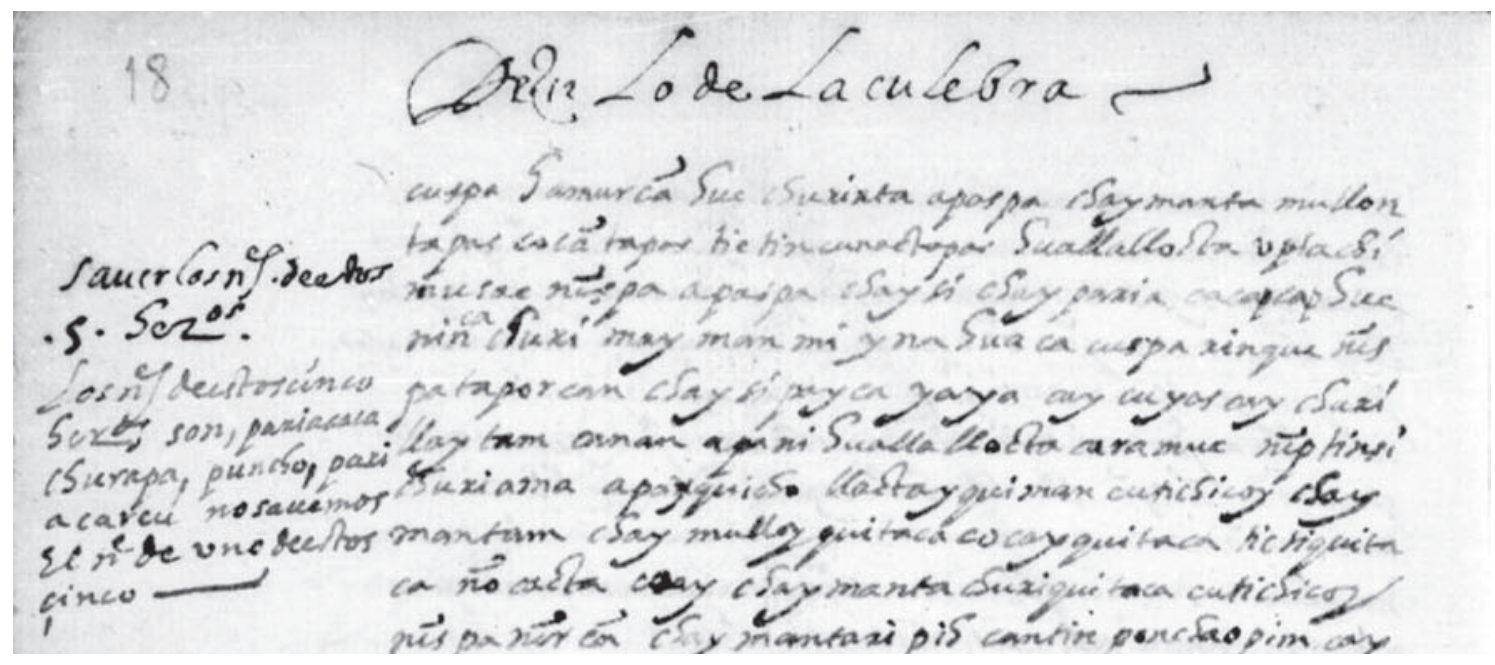

Figura 2. Detalle del margen superior izquierdo de foja 72v. Figure 2. Detail of upper left margin of folio $72 v$. 
*Dezir lo de la culebra// sauer los nombres de estos 5 hermanos // los nombres de estos cinco hermanos son pariacaca, churapa, puncho, pariacarcu, no sauemos el nombre de uno de estos cinco

*Sauer si estos son hermanos pues se dize que salieron de los huevos o si son hijos del [ilegible] hermanos o eran // * sauer como esta este sullcayllapa.

Como se puede apreciar claramente en el detalle del fragmento, los ducti y las distintas densidades en las tintas de la pluma nos permiten pensar que se trata de dos momentos escriturarios de una misma mano. Así, en una primera instancia, el informante no habría revelado los nombres de los hermanos. Después de haber leído la transcripción -probablemente-, Ávila solicitó que se investigara ese dato en específico.

A modo de hipótesis, pudieron existir distintos tipos de informantes -algunos de ellos viajando con el mismo doctrinero-, lo que explicaría la imposibilidad de averiguar el nombre del quinto hermano. El fragmento citado aparece en los márgenes del capítulo 8. Sin embargo, recién en el capítulo 16 se utiliza esta información dentro del cuerpo del texto:

En el octavo capítulo ya nos referimos a la cuestión de si los que nacieron con Pariacaca de los cinco huevos eran todos sus hermanos o si los demás eran hijos de Pariacaca. Aquí vamos a escribir los nombres de cada uno de ellos. Como narramos en el décimo cuarto capítulo, se dice que Pariacaca y los demás que nacieron de los cinco huevos, eran hijos de Cuniraya y que todos ellos a su vez poseían numerosos hermanos. Comenzando por el primero, sus nombres eran: Pariacaca, Churapa, Puncho y Pariacarco. No conocemos el nombre de uno de ellos. Aquí quedará en blanco para anotarlo cuando lo sepamos (Taylor 2008: 79).

Ahora bien, el mismo Taylor en su última edición señala:

Hasta ahora hemos hablado del "redactor" del manuscrito. Nos parece más preciso llamarlo el "autor”. ¿Cuál fue de hecho la tarea del que compuso el manuscrito? ¿ Hizo simplemente una recopilación de la tradición oral local, precursor de los etnólogos actuales? En realidad, el autor-llamémoslo Tomás- realizó una obra literaria en la que no solo transcribió los datos que le habían contado, sino que también los ordenó $y$ comentó. Tal vez inspirado por los pocos capítulos compuestos por Ávila, preparó un libro dividido en párrafos y capítulos organizados temáticamente: primero, los grandes mitos, base de la cosmología regional; luego, las tradiciones sobre las migraciones de sus antepasados y las conquistas atribuidas a dioses y a héroes divinizados quienes, según las poblaciones locales, habían fundado sus comunidades (2008: 10, énfasis nuestros).

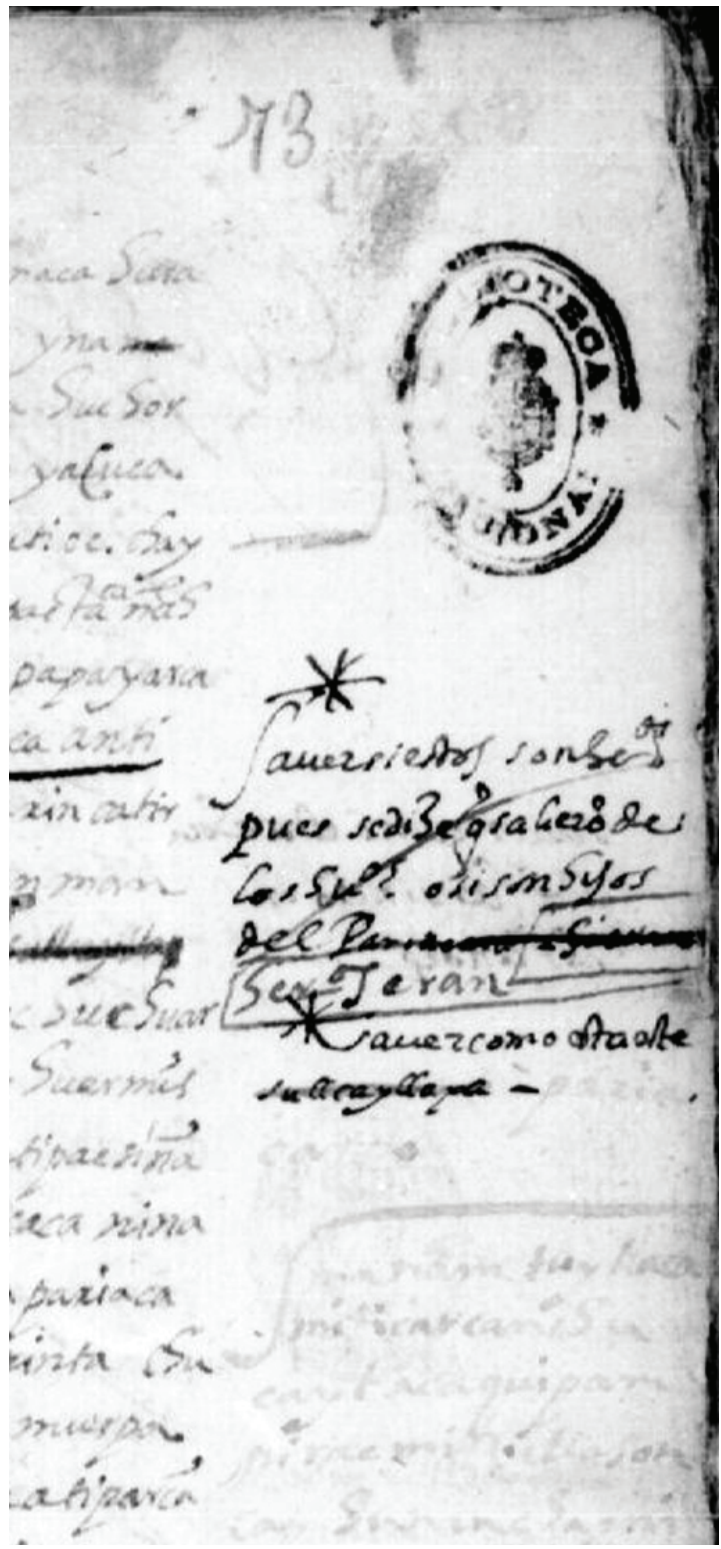

Figura 3. Detalle de margen superior izquierdo de foja $73 \mathrm{r}$. Figure 3. Detail of upper left margin of folio 73 r.

Recopilador, autor, redactor... ¿Quién desempeña qué función en las fuentes andinas coloniales? ¿Cuál es la importancia de determinar los roles de cada uno en la tradición textual andina colonial? Probablemente, no podamos responder de manera rotunda a estas preguntas aquí; sin embargo, sí se puede comenzar a esbozar algunas líneas de aproximación. Para hacerlo, es necesario abrir la mirada más allá de este manuscrito e intentar contextualizarlo, con la esperanza de que en dicho proceso 
nuevas luces alumbren estas páginas. Nuestra propuesta metodológica implica partir por estudios de caso, para luego considerar si sus características y condiciones son homologables a otros manuscritos andinos coloniales, ejercicio que precisamente buscamos llevar a cabo aquí. Si se presta atención a la cita de Taylor recién expuesta, se advertirá que el lingüista francés propone un orden de redacción que involucra a otro documento foliado en el mismo volumen que el Manuscrito Huarochirí, el Tratado y relación de los falsos errores..., supuestamente redactado por el mismo Francisco de Ávila. De acuerdo con el análisis de Taylor (2008), primero habría ocurrido la redacción del Tratado y relación y luego la del Manuscrito Huarochirí. Ya en este punto se hace evidente que para poder abordar el problema debemos sobrepasar los límites de la foja -y del manuscrito como unidad textual- y enfocar el análisis desde una perspectiva más amplia, que contemple el volumen completo.

Así, uno de los puntos de partida para este tipo de fuentes es el rol que los doctrineros, religiosos o misioneros tuvieron en la creación (término amplio, sin duda, pero que nos permite movernos con más holgura por el momento) de los textos. Recordemos que uno de los principales objetivos de la evangelización era convertir a los indígenas a la fe católica. Esto implicó, entre otras cosas, la erradicación de las prácticas idolátricas, destruyendo a sus principales divinidades y sus cultos (wak'as, monumentos, etc.). ${ }^{4}$

Francisco de Ávila tenía una agenda que iba mucho más allá de la mera recuperación de las tradiciones orales en Huarochirí. Su intención era política, ideológica y se proyectaba en el largo plazo. Ahora bien, como lo hemos señalado en las páginas precedentes, ambos documentos mencionados se encuentran encuadernados en un mismo volumen. Si se piensa que uno es la traducción -incompleta- del otro, este dato podría no ser significativo. Sin embargo, en el mismo volumen se encuentran también otros documentos, la mayoría de ellos relacionados con la cultura andina prehispánica o colonial. Además, en varios se declara expresamente que son copias o bien son autógrafos (Cristóbal de Molina, Pachacuti Yamqui), aunque casi todos ellos fueron escritos por varios amanuenses cuyas escrituras podemos reconocer, en algunos casos, en dos o más manuscritos, lo que nos lleva a problematizar la adjudicación de cualquiera de ellos a una sola figura autorial.

Estas primeras constataciones nos llevaron a visualizar el volumen 3169 no solo como una encuadernación de varios manuscritos, sino como una unidad compleja. Esta unidad se manifiesta tanto en términos de la temática que atraviesa a todos los manuscritos como en algunas de las características de su manufactura, lo que nos llevó a proponer (Martínez 2011, 2014) la existencia de un taller de escritura; es decir, una instancia de creación y/o de copia de manuscritos -todos ellos aunados bajo la temática de las creencias y culturas andinas- donde participaron varios amanuenses bajo la supervisión y/o dirección de un jefe de taller (que puede ser identificado en algunos casos con Francisco de Ávila, con Murúa o con Guamán Poma). En dichas investigaciones nos preocupamos de constatar y consolidar la evidencia etnofilológica que permitía sustentar la hipótesis de los talleres de escritura (no solo en el volumen 3169, sino también en otras fuentes documentales, como por ejemplo en El primer nueva corónica de Guamán Poma). En esta ocasión, nuestro interés es profundizar en la evidencia del volumen como unidad y relevar cierta información que, en las numerosas ediciones individualizadas de los manuscritos contenidos en dicho volumen, ha quedado relegada.

\section{VOLUMEN 3169 BNE}

En su análisis, el mentado volumen arroja datos interesantísimos relativos a la manufactura de los manuscritos y, por tanto, a las dinámicas de la creación de dichos textos. Allí se encuentran encuadernados varios documentos. ${ }^{5}$

En la primera foja, ${ }^{6}$ sin número, se lee: "Pertenece a la Bibliotheca del Reverendísimo Florez y fue de su uso". En seguida, en la foja 1r aparece una sola palabra: "Yngas". En la 1v: "Chile. Año de 1553 fue el primer rebelion de los yndios araucanos siendo gobernador valdivia mataronle con todo su canpo, desde entonces hasta oy año de 1613 no ha cessado la guerra ni cessara. Año de 1599 miercoles al amaneçer 4 de noviembre fue la destrucción de la ciudad de valdivia. vinieron sobre ella 3 mill de a cavallo y 2 mill infantes y mas de 200 arcabuzeros y 200 cotas. Arequipa. Este mesmo año fue el terremoto de Arequipa". Volveremos sobre estos datos más adelante.

En seguida, desde la foja $2 \mathrm{r}$ a $36 \mathrm{v}$ del volumen, se encuentra la Relación de las fábulas y ritos de los Yngas hechas por Christoval de Molina cura de la parroquia de nuestra señora de los Remedios de el Hospital de los Naturales de la ciudad de el Cuzco dirigida al reverendíssimo Señor Obispo don Sebastián de el Artaum del consejo de su Magestad. ${ }^{7}$ En lo que se refiere a Cristó- 
bal de Molina el Cuzqueño, podemos señalar que fue clérigo y párroco de la iglesia de Nuestra Señora de los Remedios en el Cuzco, considerado un gran quechuista. Señala Hernández (2010:25) que, "además de la Relación de las Fábulas, se tiene noticia por otros autores de la época de que escribió una Historia General del Perú, aún perdida". En términos historiográficos, Cristóbal de Molina no ha sido considerado dentro de los autores "toledanos", pues sus relatos no siguen el "criterio de deformación voluntaria de la historia incaica con miras a construir una versión satanizada de los gobernantes del Cuzco y constituir así mayores argumentos para justificar la dominación colonial" (Hernández 2010: 25) que impuso el virrey Toledo. Hacia 1570, el obispo Lartaún le encargaría que escribiera un libro sobre las costumbres, ritos y creencias incaicas, cuyo resultado es precisamente el manuscrito que aquí comentamos. Además, Cristóbal de Molina fue visitador eclesiástico en 1568 y 1575, y participó, junto al mismo Obispo Lartaún, en el III Concilio Limense. ${ }^{8}$ Teniendo estos dos aspectos en consideración, es necesario señalar entonces que la Relación ha sido datada entre 1570 y 1575, es decir, su fecha de creación sería la más temprana en relación con otros manuscritos de este mismo volumen.

Nuestra hipótesis es que el documento de Molina es una copia de un original aún no encontrado. Esta idea surge a partir de numerosos espacios que quedaron en blanco y que pueden estar indicando que el copista no entendió lo que decía el original. ${ }^{9}$ Usualmente, cuando un copista no puede entender la escritura del original, deja ese espacio para ser completado posteriormente. $\mathrm{Al}$ respecto, son destacables las consideraciones hechas por Urbano y Duviols en su edición de esta relación. Según los datos aportados por ellos, el manuscrito de Molina aparece encuadernado en el volumen $1173^{10} \mathrm{de}$ la Biblioteca Nacional de Madrid junto con otros papeles

entre los cuales aparece el Tratado de Juan Polo de Ondegardo sobre el linaje de los Incas y el manuscrito de Huarochirí, compilado por Francisco de Ávila. La letra de la Relación de Molina es del siglo XVII y similar a la empleada en el manuscrito de Ávila. Es posible que esta copia de Molina pertenezca a los papeles utilizados por Francisco de Ávila para la elaboración de sus tratados sobre idolatrías de indios peruanos o sus sermones antiidolátricos (Urbano \& Duviols 1989: 43, énfasis nuestro).

A diferencia de lo que señalan Urbano y Duviols, quienes distinguen una sola letra, en nuestro examen filológico hemos logrado identificar en esta relación al menos tres grafías distintas: la del título y dos más que se turnan en la redacción del manuscrito (Martínez 2011, 2014).

El segundo documento es: Tras[l]ado de un cartapacio a manera de borrador que quedó en los papeles de el licenciado Polo de Ondegardo cerca de el linage de los Yngas y como conquistaron, fojas $37 \mathrm{r}$ a $60 \mathrm{v}$. Se trata de una descuidada copia ${ }^{11}$ de Notables daños de no guardar a los indios sus fueros.

Ahora bien, este manuscrito es una copia, al igual que el volumen 2821 -de la misma biblioteca- de dos originales distintos aún desconocidos. Ninguno fue escrito por Polo de Ondegardo (Lamana Ferrario 2012: $26,28)$. Una comparación de ambos manuscritos permite concluir que, en algunos casos, el ms. 3169 aclara contenidos obscuros del ms. 2821; en otros, el ms. 3169 presenta blancos ausentes en el ms. 2821; en otros, el ms. 3169 presenta errores de lectura que no están en el ms. 2821; en otros, la diferencia de redacción entre ambos es evidente, pero no de contenido, "lo cual sugiere la reescritura de ideas en distintos originales" (Lamana Ferrario 2012: 30); en otros, ambos manuscritos tienen diferencias no significativas $y$, finalmente, algunas escasas diferencias significativas (Lamana Ferrario 2012: 28-31). Lamana Ferrario, a pesar del excelente estudio que realiza, confunde un grafema que permite sacar importantes conclusiones para el tema que venimos abordando (fig. 4). ${ }^{12} \mathrm{El}$ autor, en el compendio que hace de las obras de Ondegardo, transcribe el manuscrito

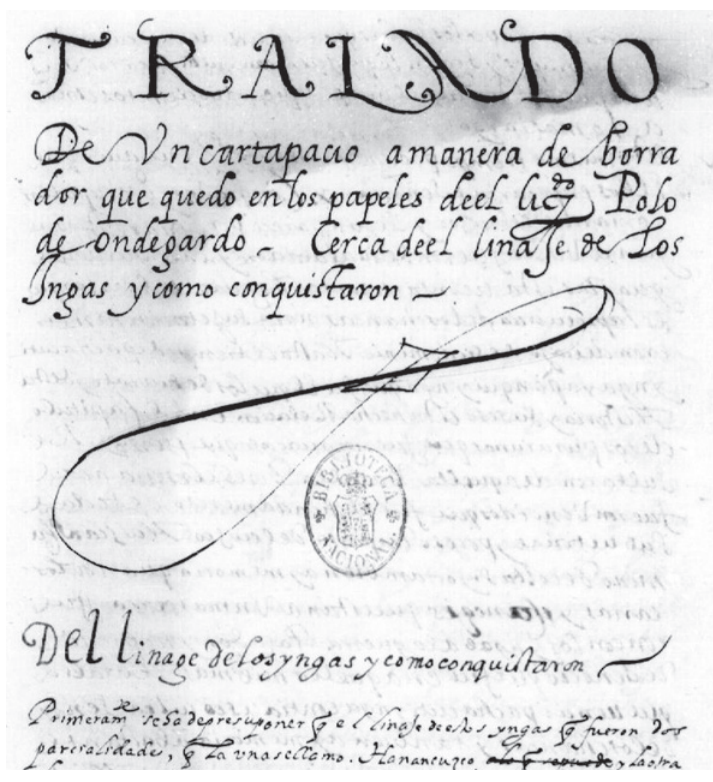

Figura 4. Foja 37r (detalle). Figure 4. Folio 37r (detail). 


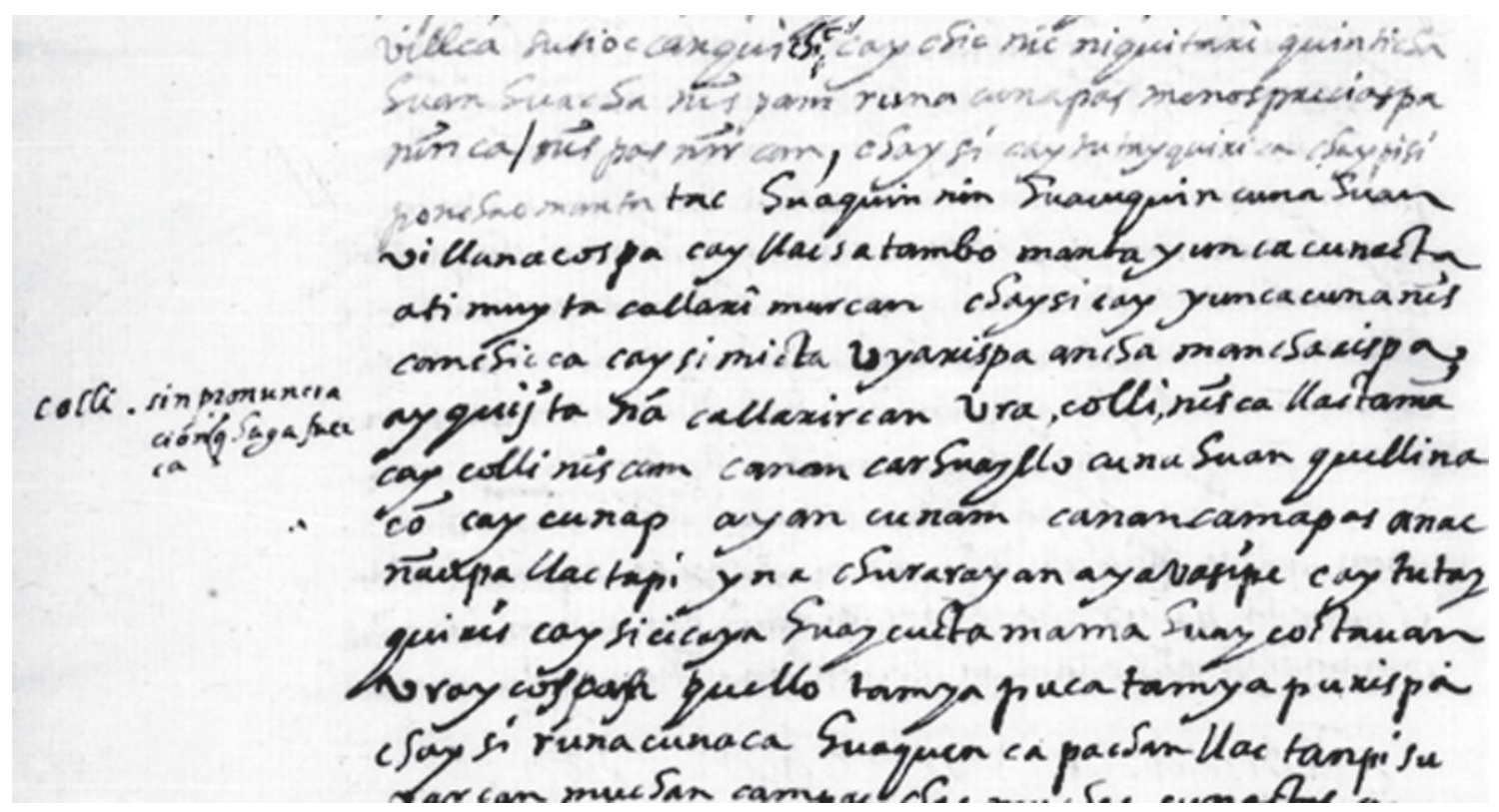

Figura 5. Foja 77v (detalle). Figure 5. Folio 77v (detail).

foliando en el volumen 3169 de la BNE como "Tratado de un cartapacio a manera de borrador $[\ldots]^{\prime 13}$

Sin embargo, como podrá apreciar el lector, el tít ulo es otro: "Tra[s]lado de vn cartapacio a manera de borrador que quedó en los papeles de el Licenciado Polo de ondegardo cerca de el linaje de los Yngas y como conquistaron". Ponemos énfasis en la palabra tra[s]lado, una de cuyas acepciones significa: "copia o reproducción de un escrito". ${ }^{14}$ Ciertamente, pareciera no tener sentido un título como "Tratado de un cartapacio", mientras que el "Tra[s]lado de un cartapacio" inmediatamente nos ubica dentro del escenario que estamos delineando, el de las copias. El texto de Ondegardo no es otra cosa sino una copia de algún cuadernillo o conjunto de papeles que en un determinado momento pasaron a manos del gestor de estos manuscritos (no consideramos que eso convierta al copista en autor ni creador de los originales, somos enfáticos en esto).

Nuestra hipótesis con respecto a la copia del Traslado de Ondegardo, luego de considerar la comparación hecha por Lamana Ferrario entre los manuscritos 3169 y 2821, es que en el taller de Ávila solo contaban con uno de los manuscritos.

Mientras Duviols (1966: 231) ha afirmado que sería el mismo Francisco de Ávila quien habría copiado el texto de Ondegardo, Lamana Ferrario sostiene que el copista del ms. 3169 no se trataría de un hablante nativo del español, pues sus errores "a menudo resultan en frases gramaticalmente incorrectas aun para los estándares del siglo XvI; en otros casos, hacen que frases que son gramaticalmente correctas no tengan ningún sentido" (Lamana Ferrario 2012: 32). Por estas razones, concluye -tal como nosotros- que Francisco de Ávila le habría encargado a alguno de sus asistentes indígenas la redacción de la copia. Sin embargo, no coincidimos con sus conclusiones cuando señala que el copista, por el hecho de equivocarse al copiar la palabra "ceques", no habría sido un hablante nativo del quechua. Por el contrario, nuestra impresión al respecto -si bien no nos permite elaborar una propuesta contundente y absoluta- es que dado el nivel de alfabetización de la población indígena general, la vacilación grafemática no es necesariamente indicio inequívoco de la lengua nativa del copista o escribiente, sino solo del estado de estandarización lingüística de la escritura del quechua. Algunas apostillas muy interesantes a este respecto son la que aparecen en las fojas $77 \mathrm{v}$ y $83 \mathrm{v}$, respectivamente. En la primera se lee "colli. sin pronunciacion que haga fuerça”, dando una clara pauta fonológica que, dado que las reglas ortográficas aún no se encontraban ni muy difundidas ni estabilizadas, era necesaria para no confundir el vocablo con otro. En la segunda, se corrige el seseo en "macahuisa" (figs. 5 y 6).

El documento que se encuentra a continuación del Tra[s]lado de Ondegardo consta solo de cuatro fojas. 


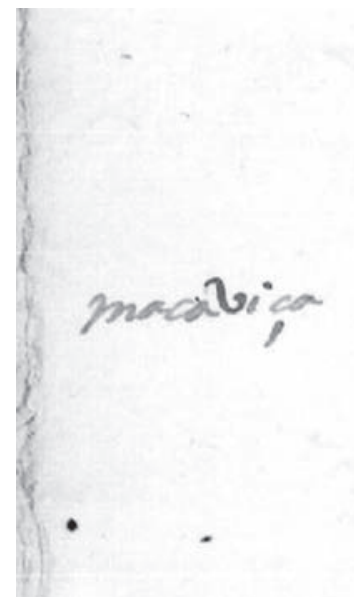

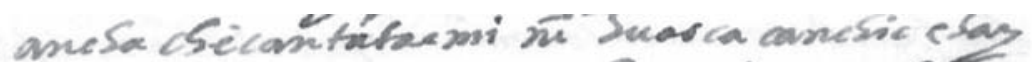

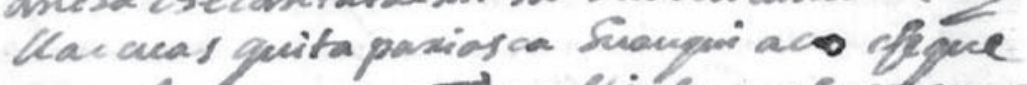

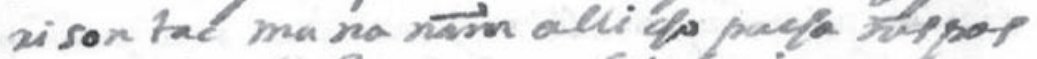

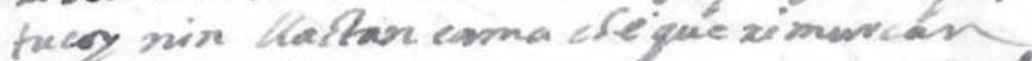

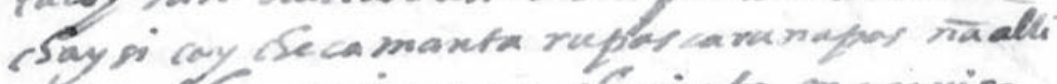

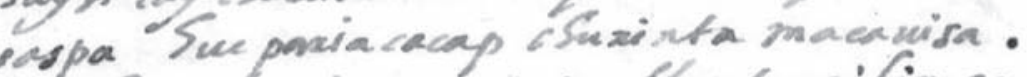
sutiorta apa uispa quintip llavempilimea. subio llai tapi craya musca cay cunaltam

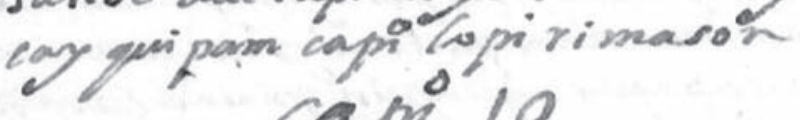

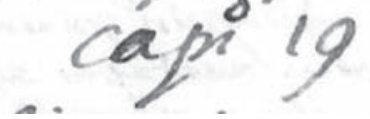

Figura 6. Foja 83 v (detalle). Figure 6. Folio $83 v$ (detail).
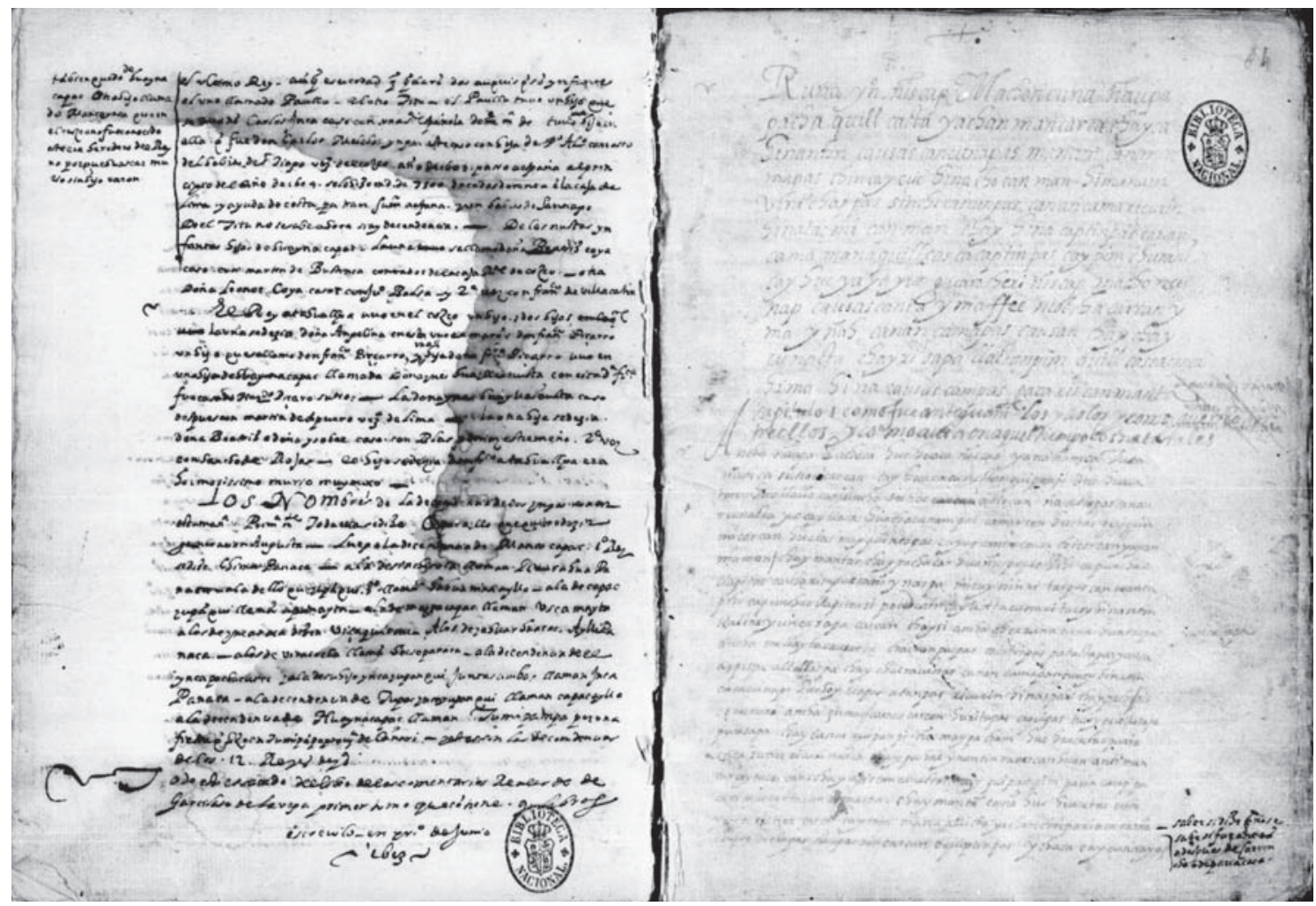

Figura 7. Foja 63 v y 64 r. Figure 7. Folios $63 v$ and 64 r.

Llamaremos provisoriamente a este documento "Origen y succession de los Yngas". Por el efecto que tuvo una filtración de agua sobre sus fojas, podemos inferir que durante un tiempo formó parte del mismo conjunto de documentos que el de Molina y el de Ondegardo. La filtración de agua comienza a ser perceptible en la foja $31 \mathrm{v}$ (documento de Molina) y parece haberse originado precisamente en la foja $65 \mathrm{v}$, donde termina este breve documento anónimo, tal como se puede apreciar en la reproducción de las fojas $63 \mathrm{v}$ y $64 \mathrm{r}$ (fig. 7). 
Cabe destacar esta mancha, pues nos permite concluir algunos aspectos sobre el momento en que los documentos fueron foliados en un solo volumen (el que formó parte de la biblioteca del padre Florez, y previamente de Ávila). En principio, podríamos establecer que los tres primeros documentos constituyen parte de un grupo documental. Puesto que hemos determinado que tanto el de Molina como el de Ondegardo son copias, se puede asumir que el o los copistas se dedicaron primero a un conjunto y luego al siguiente (no podemos aventurar todavía una hipótesis sobre cuál puede haber sido el primero).

Es muy interesante notar el siguiente hecho. En la anotación marginal que se encuentra en la foja $1 \mathrm{v}$, podremos constatar que se trata de la misma mano de quien anota también, marginalmente, el texto de Molina. Más interesante aún es advertir la índole de la segunda apostilla. Veamos primero ambos segmentos (figs. 8 y 9 ).

El análisis filológico nos permite señalar que quien hizo ambas anotaciones es la misma persona, hecho constatable en el ductus de letras o grafemas como la $/ \mathrm{h} /$, $/ \mathrm{q} /, / \mathrm{p} /$, etc. El texto transcrito del detalle de la figura 9 , "Lo que que [sic] hizieron los 2 hijos de Pachayacheo o Pachacamac", nos permite vincular la función de este escriba con otras anotaciones fecundas en el resto del

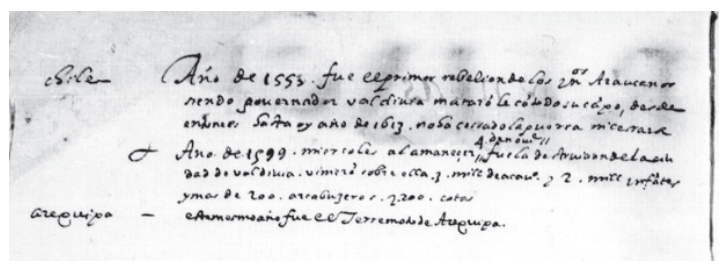

Figura 8. Foja 1v. Figure 8. Folio 1v.

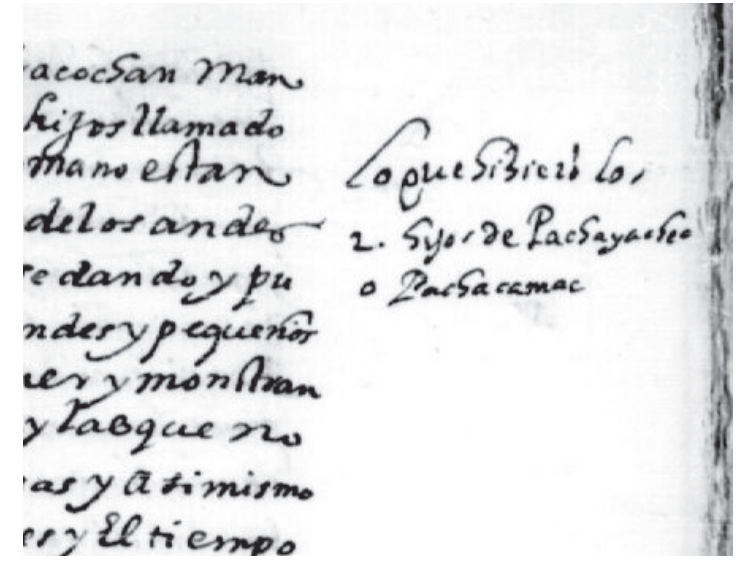

Figura 9. Detalle foja 4r. Figure 9. Detail of folio $4 r$. volumen 3169. Además, como se puede apreciar en las siguientes imágenes, quien hizo dichas apostillas también escribió el breve documento de 4 fojas antes referido y que hemos nombrado "Origen y succession de los yngas" (figs. 10 y 11).

En seguida, en el volumen 3169 se encuentra el llamado Manuscrito Huarochirí, fojas 64r a 114r. Tal como señala Zanelli:

El Manuscrito de Huarochirí es el único documento quechua conocido donde se recogen tradiciones y mitos de una comunidad andina durante la época colonial. Este texto es el resultado directo del proceso de extirpación de idolatrías emprendido por Francisco de Ávila, cura doctrinero de San Damián, en la provincia de Huarochirí perteneciente al repartimiento de Lima entre 1608 y 1614. El documento fue redactado en quechua por alguno o algunos de los indios que acompañaron al extirpador Avila, seguramente en calidad de intérpretes, durante dicho proceso (Zanelli 2012: 90, énfasis nuestro).

Dada la complejidad e importancia de este manuscrito, nos detendremos un poco en su tradición crítica. Nos referiremos, entonces, a la historia textual del Manuscrito Huarochirí y a algunas de las interpretaciones que ha suscitado su conformación textual. Las primeras informaciones sobre la existencia del Manuscrito Huarochirí datan de 1879, gracias a Marcos Jiménez de la Espada, quien publica Tres Relaciones de Antigüedades peruanas, en que señala: "parece que el padre Ávila no escribió todo este tratado de su cosecha, sino que traducía, adicionándolo e ilustrándolo con propias observaciones, un texto original, recogido de personas que habían vivido en los errores y ritos de la gentilidad peruana, antes que Dios las alumbrase" (1879: xxxIV). ${ }^{15}$

Sin lugar a dudas, una de las más importantes ediciones es la elaborada por Arguedas (1966). Aunque en ella el criterio lingüístico -primordial para poder determinar estados de lengua y sujetos escribientes- no prima, el criterio literario es desarrollado con magnificencia.

León Llerena ha intentado resumir las distintas hipótesis esgrimidas para tratar de explicar la factoría del manuscrito. De acuerdo con ella, a pesar de esta extensa tradición literaria, en los distintos estudios realizados sobre el Manuscrito de Huarochirí aún no se ha llegado a un consenso sobre el problema de la relación entre el autor, el editor, el redactor y el compilador del manuscrito. Hasta el momento, existirían dos hipótesis. La primera es la de Duviols, "quien plantea que quien escribió y editó el texto sería un indígena bilingüe convertido al 


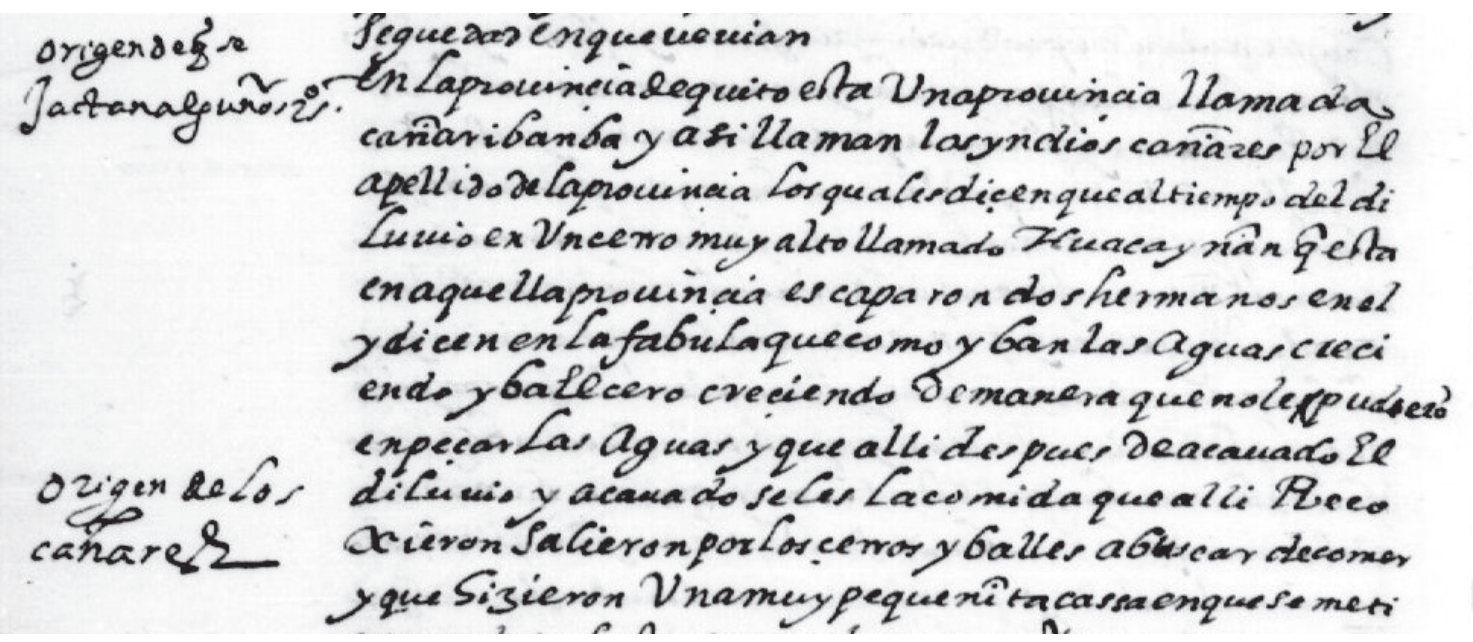

Figura 10. Detalle foja 4v. Figure 10. Detail of folio $4 v$.

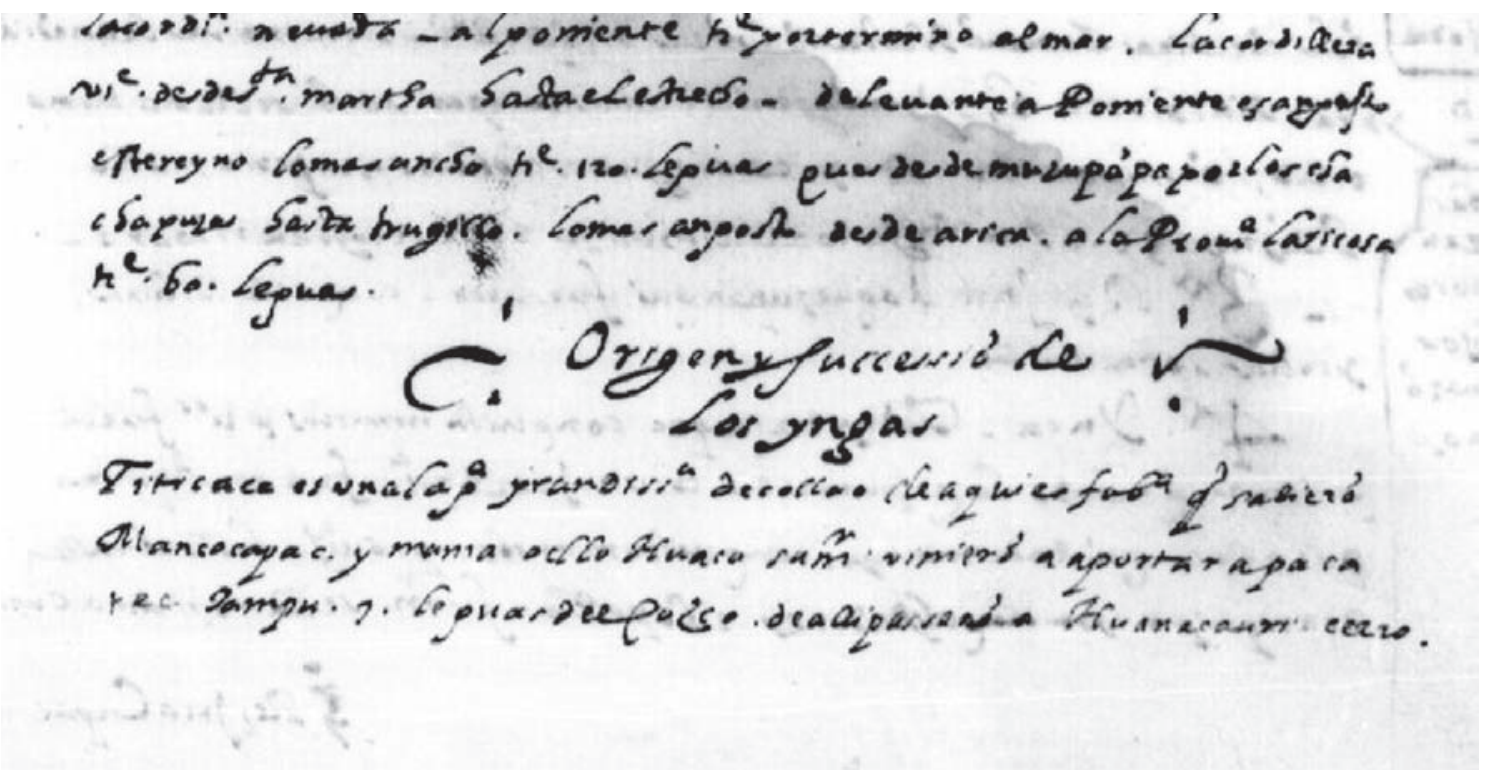

Figura 11. Detalle foja 61r. Figure 11. Detail of folio 61r.

cristianismo. Ávila habría supervisado parcialmente la producción del manuscrito - lo que quedaría registrado en algunas notas en español hechas al margen del textopero no fue su autor, y esto quedaría demostrado en Tratado... que el propio Ávila empieza a escribir en 1608" (León Llerena 2007: 36). A esta hipótesis se opone la de Taylor, quien considera que las acotaciones presentes en los márgenes del manuscrito (tanto en español como en quechua) "indicarían que el compilador de la información oral y editor fueron la misma persona aunque el escriba pudo ser otra persona" (León Llerena 2007:
36). León Llerena añade que ambos autores, Duviols y Taylor, coinciden en pensar que Francisco de Ávila no fue el autor del manuscrito y que "es evidente que la factibilidad de cualquiera de estas u otras hipótesis depende en gran medida de la resolución de una serie de problemas técnicos [etnofilológicos, entendemos nosotros] del manuscrito" (León Llerena 2007: 36).

Sin embargo, pensamos que el asunto es bastante más complejo de lo que señala esta autora. Sobre la primera hipótesis, de que quien escribió y editó el texto sería un ladino (hipótesis que, entonces, también habría 
compartido Arguedas), es necesario señalar que de ella se han desprendido otras, entre las cuales cabe señalar las de Taylor en sus distintas ediciones (1987 y 2008) y la de Durston (2007). En 1987 Taylor, como ya lo hemos apuntado en numerosas oportunidades, publicó la primera edición con criterio lingüístico, mención obligada de cualquier estudio que se refiera a este documento colonial. Al decir de Salomon sobre la edición de Taylor de 1987:

Tal vez movido por la modestia, Taylor ha velado en parte sus esfuerzos de interpretación. La introducción no aborda de manera directa algunas cuestiones ineludibles de interpretación que antes intimidaron a los lectores noveles. ¿Cuántas voces individuales cobran aquí expresión? ¿Cuándo se trata de un yo colectivo? ¿Debemos entender que los mitos y ritos pertenecen a un sistema armónico o reúne acaso este libro un conjunto de cultos cuyas respectivas tradiciones no hacen sino contradecirse? ¿Qué partes debemos atribuir al redactor o editor desconocido? ¿Puede nuestra lectura trascenderlo para percibir las rupturas de tiempo voz y creencia a partir de las cuales modeló el autor la unidad de su texto? (1991: 464-465, énfasis nuestro).

Es muy interesante la pregunta que se plantea Salomon sobre la individualidad y/o colectividad de la autoría en el contexto de las fuentes andinas coloniales. ¿Implica esto, por el hecho de tratarse de una factoría colectiva, que no existiría un autor? O bien, ¿podemos, a partir de estos datos, replantearnos la definición del autor en el contexto de las fuentes andinas coloniales?

El mismo Taylor reflexiona sobre este punto, preguntándose: “¿Cuál fue de hecho la tarea del que compuso el manuscrito? ¿Hizo simplemente una recopilación de la tradición oral local, precursor de los etnólogos actuales?" (2008: 10). A partir de la evidencia que él analiza, llega a la conclusión de que Tomás "realizó una obra literaria en la que no solo transcribió los datos que le habían contado, sino que también los ordenó y comentó. Tal vez inspirado por los pocos capítulos compuestos por Ávila, preparó un libro dividido en párrafos y capítulos organizados temáticamente [...]” (2008: 10).

Asimismo, al abrigo de las conclusiones hechas por Rowe, Durston (2007) plantea, basándose por un lado en el Manuscrito Huarochirí y, por otro, en la petición hecha en Sunicancha por Cristóbal Choquecasa, que el autor del Manuscrito Huarochirí sería el mismo cacique don Cristóbal, mencionado en los capítulos XXI y XXII:

Recent commentators have tended to approach it as a collective work in which a number of people were involved during different stages of redaction, so the question appears somewhat moot. This essay attempts to throw new light on the problem by re-examining the evidence on the composition process and by analyzing similarities between the нм and a 1608 Quechua petition written in Sunicancha, Huarochirí by the Indian nobleman (curaca) and scribe Cristóbal Choquecasa. Choquecasa has been identified as someone who had a major role in the genesis of the нм by Antonio Acosta, Willem Adelaar, and Frank Salomon (Acosta 1987, 597; Adelaar 1997, 136; Salomon 1991, 26, 34). However, only the recently deceased John $\mathrm{H}$. Rowe went as far as suggesting that the HM was actually written by Choquecasa (2007: 227).

Más adelante, Durston añade que las acotaciones marginales parecen haber sido escritas completamente por una misma persona, aunque indica que es necesario admitir que si bien la escritura no es completamente uniforme, las diferencias de trazos no significarían la existencia de más escribas. Asimismo, también reconoce que existen diferencias de estilo entre los dos suplementos -escritos más rápida y descuidadamente- que se encuentran al final del manuscrito y los capítulos propiamente tales. En términos lingüísticos (dialectológicos) y ortográficos, considera que el Manuscrito Huarochirí presenta uniformidad en toda su extensión. Además, supone -al igual que nosotros- que las notas marginales, muchas de las añadiduras o aclaraciones que se encuentran en el manuscrito, son producto de la mano de Francisco de Ávila, , de tal manera que "the scribe can be seen replying directly to one of Avila's questions in Spanish (fol. 72v) and notes that reflect an editorial process leading to a new version, almost certainly Avila's Tratado" (Durston 2007: 230). ${ }^{16}$

En nuestro análisis filológico hemos identificado, hasta el momento, y además de la de Ávila, dos manos que no se distinguen por el ductus de las grafías -notamos algunas diferencias en el ductus de /j/, /h/-, sino que por la disposición, orden y uso del espacio de escritura. A diferencia de los autores antes revisados, consideramos que quien escribe los complementos y quien elabora el resto del manuscrito son personas diferentes. Aun cuando es cierto que el análisis del ductus debe complementarse con el lingüístico y estilístico, creemos que los datos aquí aportados pueden contribuir al análisis y estudio de los procesos de conformación textual y autorial de todos estos manuscritos.

Tal como se puede apreciar en las siguientes figuras (12 a 14), este manuscrito da cuenta de un complejo proceso "editorial". Son varias las manos que intervienen en su elaboración y corrección. Además, tal como se nota en la figura 14, corresponde a una copia, pues en una 


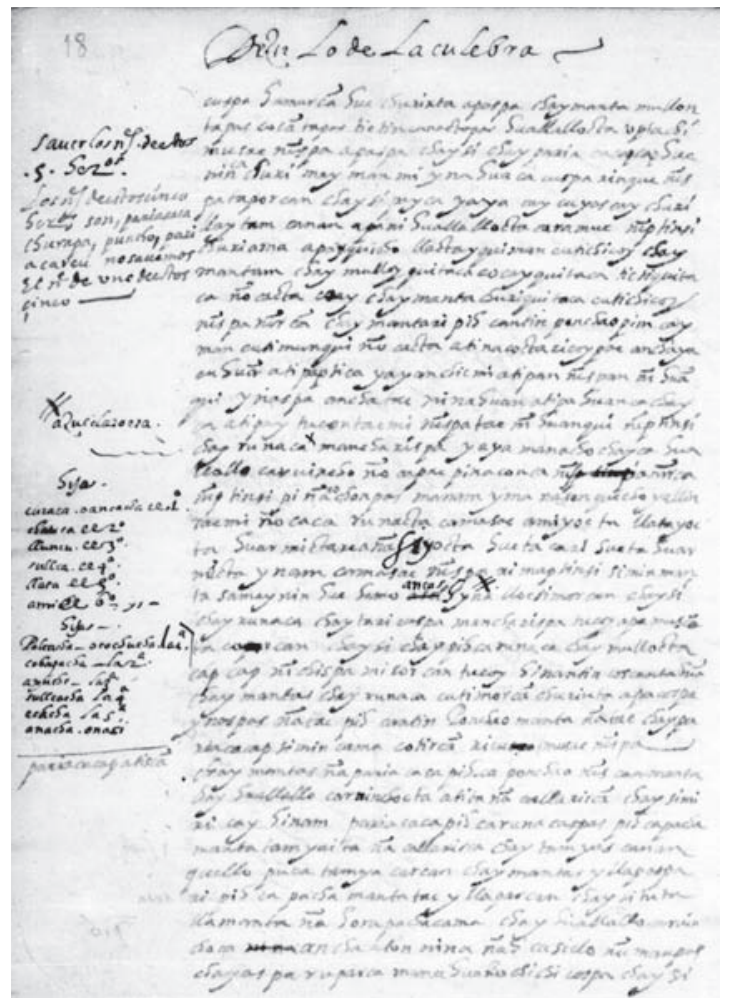

Figura 12. Foja 72v. Figure 12. Folio $72 v$.

de las líneas el amanuense no fue capaz de descifrar el escrito original y dejó el espacio en blanco.

En la figura 14a, aparte del espacio en blanco -señal de una lectura inconclusa-, en el margen izquierdo de la foja aparece escrito dos veces, de la mano de Ávila, la palabra "ojo", probablemente señalando una corrección. A la misma altura del primer "ojo" -que por lo demás está tachado-, se encuentra la enmienda que realiza al completar el enunciado añadiendo la palabra huaycho. Tres líneas más abajo, nuevamente el espacio en blanco con la palabra "ojo" en frente. A estas señas de copia se añaden dos posibles enmiendas ya corregidas frente a los títulos de los capítulos 14 y 15 y, por ejemplo, la añadidura de la palabra tamtañamca (figura 14b), en la foja 67r, en las líneas 3 y 11 (cf. Taylor 2008: 195). ${ }^{17}$

Ahora bien, a partir del estudio de las variantes asociadas a los distintos escribas o copistas, además de las acotaciones hechas por Ávila y de los "errores" de los copistas, adicionados al contexto de encuesta que mencionamos al principio de este artículo, creemos que es importante distinguir $-\mathrm{O}$, al menos, poner una nota de cautela a la hora de determinar- los roles en esta escritura.

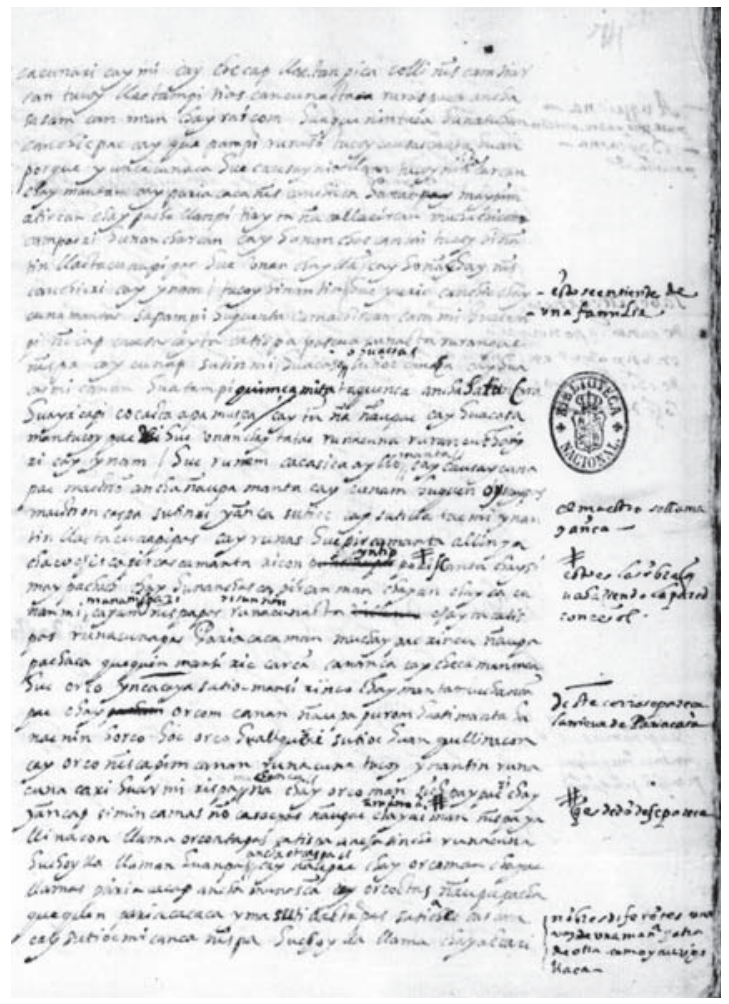

Figura 13. Foja 74r. Figure 13. Folio $74 r$.

En la reconstrucción del proceso, que nosotros hemos podido llevar a cabo, se pueden plantear los siguientes considerandos:

- Por un lado, parece plausible que el Manuscrito de Huarochirí, en su concepción textual, sea un producto ideado por Francisco de Ávila. Esto es, visto desde un punto de vista estructural del texto (podríamos decir, de disposición de la información y del tipo de información).

- En segundo lugar, si contemplamos las características procedimentales de los interrogatorios o cuestionarios en el contexto evangelizador, es lógico pensar que Ávila hubiera recorrido la zona de Huarochirí acompañado de varios ayudantes indígenas ladinos. Pero la pregunta que surge aquí es muy importante: ¿eran necesariamente los indios ladinos que lo acompañaron en la campaña los mismos que después se dedicaron a la redacción del manuscrito? Desgraciadamente, no tenemos la respuesta a esta pregunta, pero creemos fundamental explicitarla como un punto de quiebre en esta relación entre el editor, el autor, el escriba, el ladino, etc. 


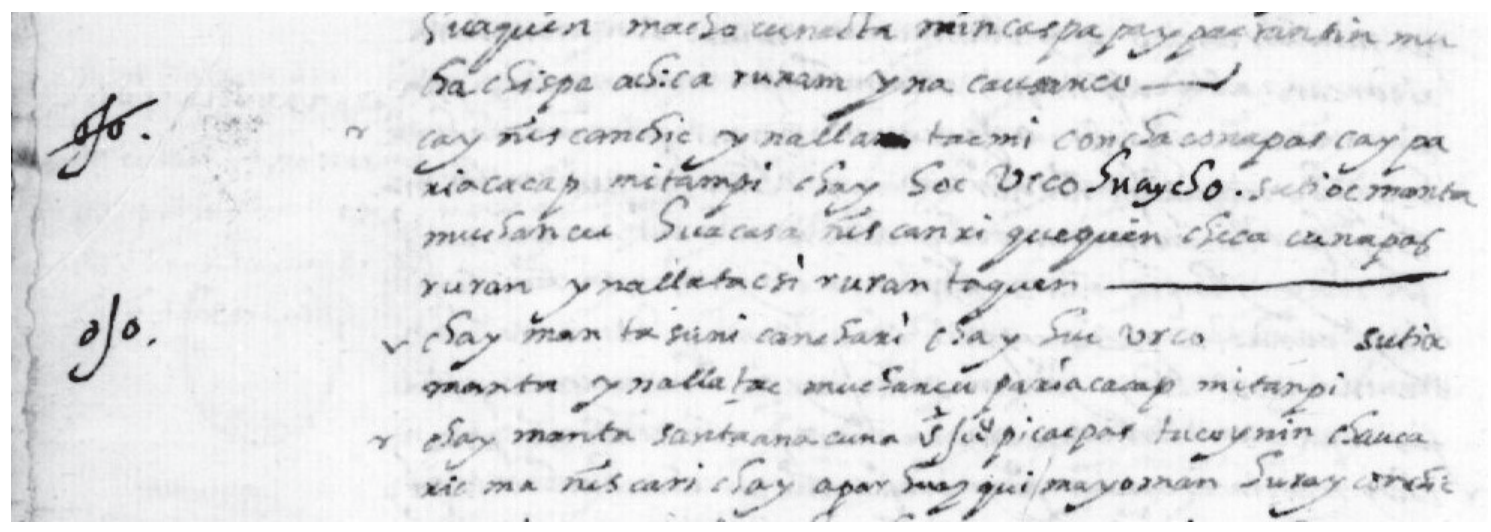

Figura 14a. Foja 75v. Figure 14a. Folio $75 v$.

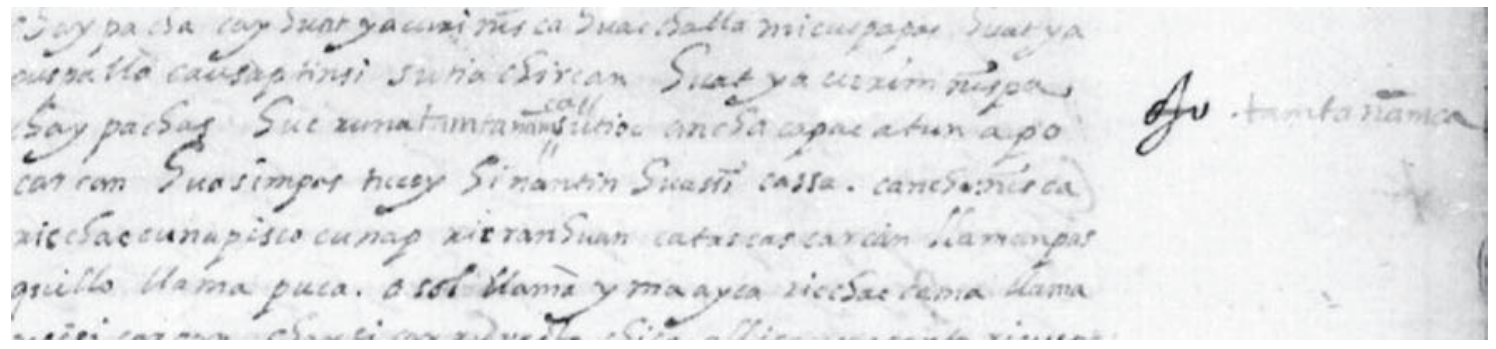

Figura 14b. Foja 67r. Figure 14b. Folio 67 r.

A continuación del Manuscrito de Huarochiríse encuentra un manuscrito que consta de una sola foja, $114 \mathrm{v}$, con una sola grafía (fig. 15). Presentamos la transcripción completa de esta foja pues arroja interesantes antecedentes sobre las distintas etapas del proceso escriturario.

El señor fran ${ }^{c o}$ demiranda es la persona por // quien escriví a US ${ }^{a}$ elor dinario passado // suplicándole fauoreçiesse en essetribunal // en las pretensioones [sic] quetiene de dos pleitos enqquele han // puesto hinjustamente ciertas personas mal intencionadas // y para queU Se tenganoticia particular delelos // dih $^{c}$ os [sic] pleitos y de su mucha justiçia que ano tenerla // tande suparte nomme empeñara enesta interçession ein// cord bemente lo quehaçe en su fauor el el princip[a]1// pleito es sobre a compra de un juro de // quinientos y treintayochomil y cinquenta maravedís // derrenta en cada Unaño arrazon dehaveinte// mil el millar situados enlas al caualas // desta çiudad ysupartido quelebendio Thomas //demontessinos depossitario gueneral dela ciudad // deSevilla el año passado demil y seis // cientos y sesentaydos como constay parece // Señor Sanntiago Unico patron Br deguerras // del rey mi señor señor [sic] Santiago Unico // patron quellebalauandera delrey miseñor // Jesus marialuz del dia tu meguias amimano // para queyo salga muy buenes cribano de // menudo y demediano amenJesus (énfasis nuestro).
Quisiéramos poner énfasis en las dos últimas líneas de este documento. Allí, quien escribe da cuenta de que está realizando un ejercicio de escritura que le permitirá ser "muy buen escribano de menudo y de mediano". ${ }^{18}$ Ahora bien, un detenido examen de los ducti de los distintos documentos que componen este volumen 3169 nos permite concluir que quien escribe esta foja es también quien escribe la apostilla de la foja 91r del volumen (que corresponde a la $55 \mathrm{r}$ del $M H$ ) y que se llama Thomas... (fig. 16). Se trata, además, del autor de algunas de las apostillas presentes en la copia del texto de Cristóbal de Molina (f. 5v, figura 17), pero que podría ser el mismo autor del ensayo de escritura que aparece en la foja $1 \mathrm{v}$ comentada más arriba.

De la foja $115 \mathrm{r}$ a la 129r se encuentra el Tratado $y$ relación de los errores, falsos dioses, otras supersticiones $y$ ritos diabólicos en que vivían antiguamente los indios de las provincias de Huaracheri, Mama y Chaclla y hoy también viven engañados con gran perdición de sus almas. Una edición completa de este tratado apareció en Arguedas (1966). Como se puede apreciar fácilmente en el fragmento de la foja 122r ofrecida a continuación (fig. 18), también es una copia. 


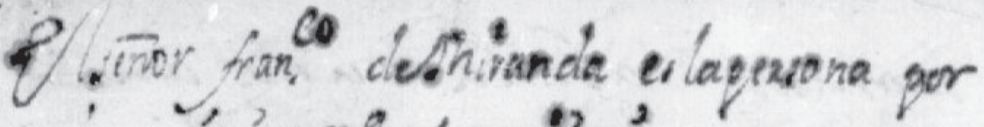

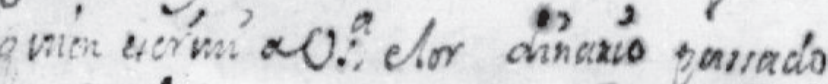

Nubicancicle fanoreciesse encise Sribunat en lw purensibones querient de dos pléio enqquelehan, pulifo nim. usoramente ciertas dexionas mal inteneronadas to

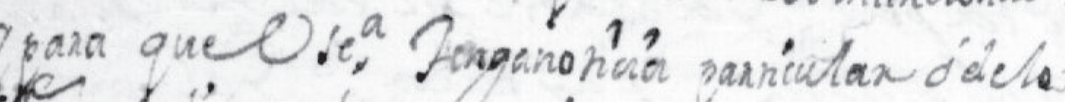

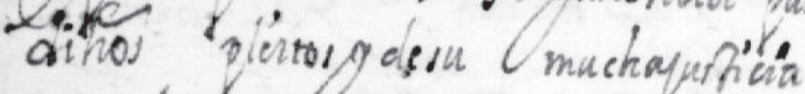
- $r$ - que ano Fenería Fande cupare nomme empenara eneifa moteriesion aín Qrebemente lo auehace enintacior etelé, Picito ensobrela Comprade Unduro de amimentor graeintayochs min quinquenea maxiucíns léexsenta encadio Unaño axrafon clehauainte

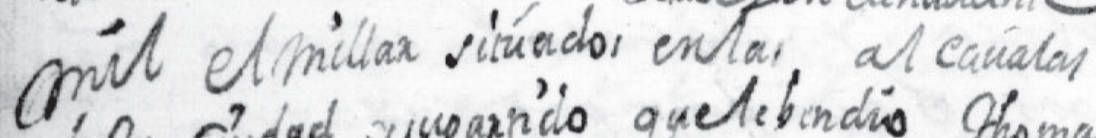
dista clided zuruaricio quelebindiso Thomas demoncerisinor deforivtario queneral dela cinctad ay coirla elaso goes cientos querentaydos comro confaryparee

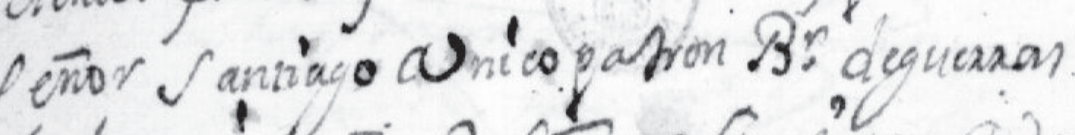
del reymi viñor Ceñor cantrago Cinco pathon quellesialanandera delvey âtiveñax.

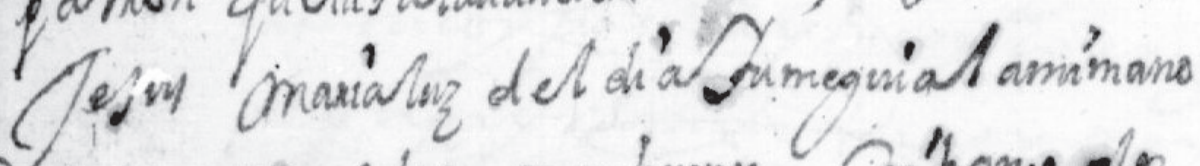

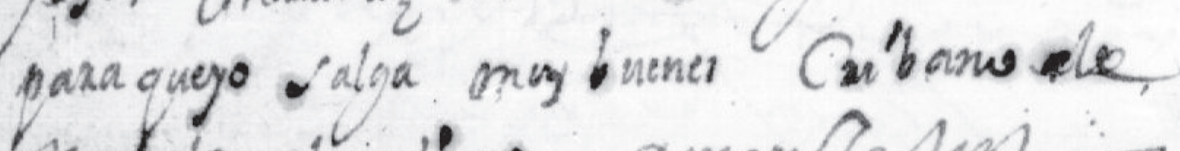
Muntodo géermediano amensejwi? 


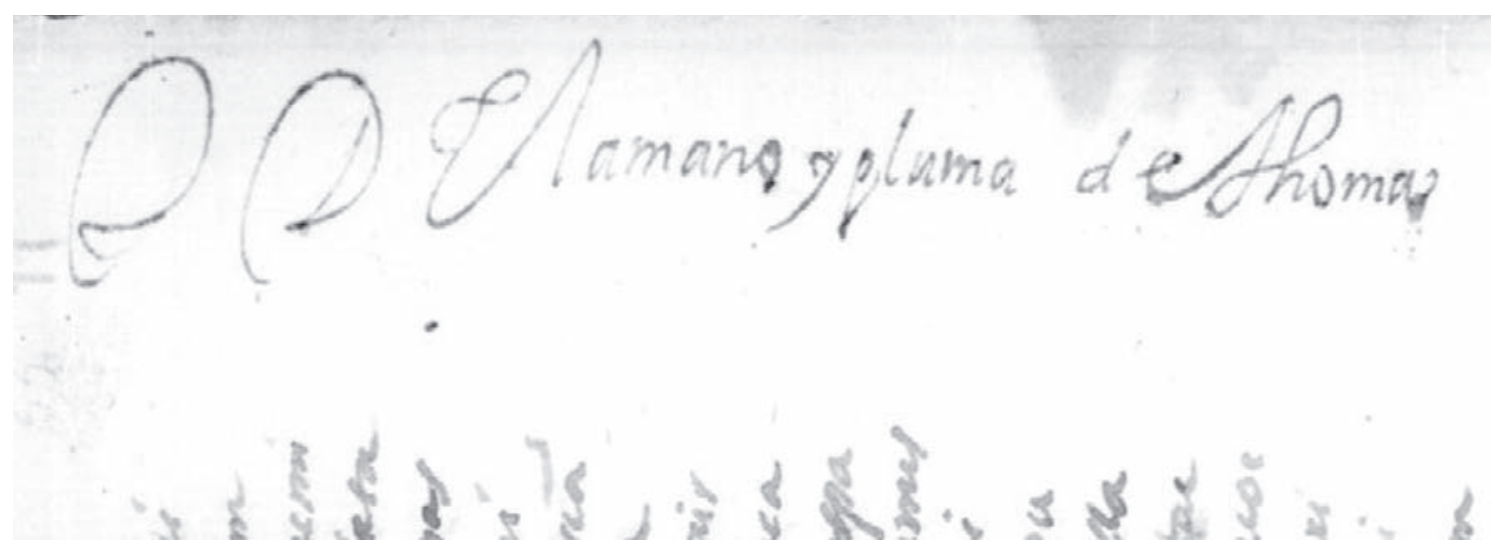

Figura 16. Detalle foja 91r. Figure 16. Detail of folio $91 r$.

Si bien no presenta rúbrica del padre cuzqueño, Jiménez de la Espada señala que es de puño y letra de Ávila (Duviols 1993: 16). En ninguna parte del manuscrito se adjudica la autoría grafemática a Ávila, sino que habría sido "recogido" por el extirpador:

Recogido por el doctor Francisco de Ávila, presbítero (cura de la dotrina de Sanct Damián de la dicha provincia de Huaracheri y vicario de las tres arriba dichas) de personas fidedignas y que con particular diligencia procuraron la verdad de todo, y aun antes que Dios las alumbrasse vivieron en los dichos errores y exercitaron sus ceremonias. Es materia gustosa y muy digna de ser sabida para que se advierta la grande ceguedad en que andan las almas que no tiene lumbre de fee, ni la quieren admitir en sus entendimientos. No se refiere al presente más que la historia, será nuestro Señor servido que el dicho doctor la ylustre y adorne con declamaciones y notas que serán agradables si Dios le diere vida (foja 117r, énfasis nuestro). ${ }^{19}$

Nuestro análisis filológico coincide con el de Jiménez de la Espada, aunque no por ello deja de plantear interrogantes al respecto, especialmente por las únicas evidencias de copia. Nos explicaremos. Tal como señalamos recientemente, existe un espacio en blanco que da cuenta de una lectura que el copista o amanuense no pudo realizar porque no entendió lo que decía el original. De aquí se despliegan dos problemas filológicos. El primero es que el Tratado y relación... sería también una copia, por lo tanto debe haber existido un original que puede haber contenido la traducción de todos los capítulos del Manuscrito de Huarochirí. El segundo dice relación con el espacio en blanco en sí, que puede estar mostrando, como lo acabamos de decir, una dificultad en la lectura. Pero ¿cómo es que el mismo Ávila -o los amanuenses que trabajaban con él-

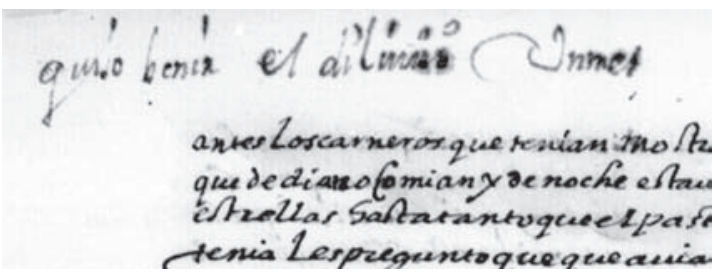

Figura 17. Detalle foja 5v. Figure 17. Detail of folio $5 v$.

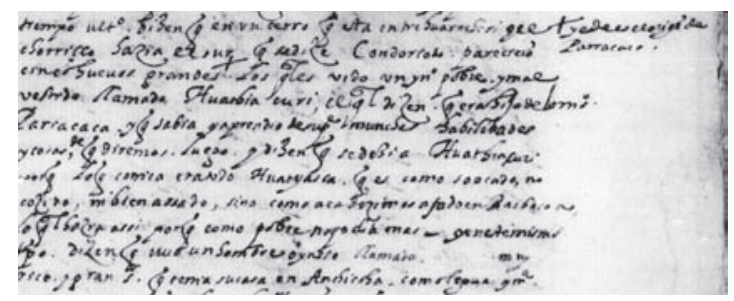

Figura 18. Detalle foja 122r. Figure 18. Detail of folio $122 r$.

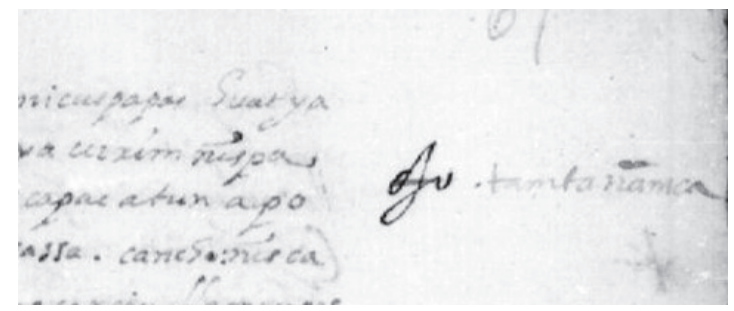

Figura 19. Foja 67r Figure 19. Folio 67r.

no pudo leer el nombre de Tamtañamca si en el mismo Manuscrito Huarochirí aparecía su nombre como nota marginal (tal como se aprecia en la figura 19, foja 67r) $\mathrm{y}$, recordemos, casi todos los críticos que han trabajado con este manuscrito han coincidido en adjudicarle a Ávila la autoría de las anotaciones marginales? ¿Nos encontramos frente a una nueva mano? 
Ahora bien, como lo venimos señalando, nuestra hipótesis es que el Manuscrito de Huarochirí nace en el contexto de un proceso cuyo formato de base parece haber sido un cuestionario. A pesar de que pueda resultar evidente, cabría señalar que a cada pregunta que se formulaba, se recibía una respuesta (de variada extensión). Dichas respuestas eran emitidas, obviamente, de forma oral y no escrita, entonces los ladinos que acompañaban a Ávila deben haber ido transcribiendo las distintas respuestas que recibían en cada lugar. Ello da lugar para plantear que este manuscrito habría permeado, de alguna manera, ciertos rasgos de oralidad que se manifiestan escriturariamente, dando cuenta también de la tensión que existe entre la preconcepción textual que tenía Ávila del orden de la información o del relato y el orden en que recibió la información o las características del relato andino oral en lengua nativa. Sin embargo, la pregunta queda sin respuesta: ¿ por qué no pudo leer el nombre de Tamtañamca?

Entre las fojas $131 \mathrm{r}$ y $174 \mathrm{v}$ se encuentra la Relación de antigüedades deste reyno del Pirú. Históricamente, este texto ha sido atribuido a Joan Pachacuti Santa Cruz Yamqui Salcamaygua, en virtud de las líneas iniciales del manuscrito, escritas en primera persona, aunque el documento no presenta rúbrica. Coincidimos con Navarro (2007) al señalar que tres son las manos que intervienen en él: la de Ávila, que hace algunas anotaciones al margen o glosa ciertos términos; y otras dos que alternan hasta el folio $11 \mathrm{v}$, una de las cuales continúa hasta el final y corrige lo escrito por la otra (Navarro 2007: 15). ${ }^{20}$ Si fuese la mano de Pachacuti esta última que termina y corrige el documento, ella no es en cambio la que señala en la primera foja la autoría, por lo que -al menos en lo que atañe a aquellas once primeras fojas- nos encontraríamos frente a un dictado o copia. No aparecen en este manuscrito las mismas evidencias que nos permiten señalar en los otros casos que se trata de copias. ${ }^{21}$ Duviols señala que "como se sabe que la relación de Huarochirí debió promoverla o encargarla Ávila con miras prácticas, es legítimo preguntarse si la relación de Pachacuti no fue compuesta en circunstancias análogas. Desgraciadamente el examen del manuscrito de Pachacuti -que se ofrece en forma de borrón [borrador] y parece ser original [...] por sí solo no nos autoriza a asimilar las circunstancias de su redacción a las de la relación de Huarochirí" (Duviols 1993: 17-18). ${ }^{22}$

\section{DE LA EVIDENCIA TEXTUAL A LAS DIVERSAS NOCIONES DE ESCRITURA}

La evidencia textual presentada a lo largo de las páginas precedentes es, sin duda, un mero ejercicio metodológico aplicado solo a un corpus documental, cuyas conclusiones deben, por lo tanto, tomarse con cautela al momento de ser proyectadas a otros documentos de la época. Empero, también este análisis nos permite vincular las prácticas escriturarias subyacentes con otros datos de índole histórica. Nos referimos, por una parte, a las referencias encontradas en los lexicones coloniales bajo las distintas voces que hacen referencia al campo semántico de la escritura. A pesar de que en los lexicones coloniales el campo semántico asociado a este vocablo es más bien reducido, es posible rescatar algunas nociones importantes. Por ejemplo, en el Arte de la lengua general del Perú (anónimo) aparecen las voces quellcani, quellcacuni, "escriuir, o debujar"; quellcana, "pluma, o escriuanias"; quellcaycamayoc, "escribano"; quellcachini, "hazer escriuir"; quellca ricuc, "el que sabe leer"; quellca yachac, "el que sabe leer y escreuir".

González Holguín (1608) señala las siguientes voces. Por un lado, aquellos objetos que se relacionan con la escritura, como quellca, "papel carta o escriptura"; quellcascappacha, "vestido pintado o bordado v labrado" y quellcanacuna, "Escriuanias, y los instrumentos de escriuir o de pintar". En este primer conjunto vemos cómo se permean, por ejemplo, las prácticas indígenas más asimilables a la escritura -la pintura y tejido-. Por otro lado, se encuentran las acciones relacionadas con la escritura, tales como quellcarpayachini, "escriuir lo que se va dictando"; quellcar payachispa yachachini, "enseñar la theologia dictándola"; simi huan camalla yachachini mana quellcarpayachicuspa, "enseñar a viua voz y no dictando" y quellccani qquellccacuni, "escriuir debuxar pintar". Parecen destacables estas voces en el sentido de que rescatan instancias de escritura donde participarían un individuo que dicta y otro que escribe. El proceso de dictado, en tanto, parece haber tenido dos formas: una que podríamos denominar "literal", es decir, de lectura en voz alta, y otra "a viva voz", que se entiende sin un texto dictado, es decir, "improvisado" ${ }^{23}$

También se encuentran términos que designan a las personas relacionadas con la escritura, como quellcaricuk, "el que sabe leer"; quellcayachak, "el que sabe escribir"; alliqquellcaytayachak, "el buen escriuano"; quellcaycamayok, "el escriuano de officio, o el gran escriuidor"; 
quellcak, "el que escriue" y ppacha qquellcak, "bordador". Finalmente, en el lexicón de González Holguín solo encontramos una voz para la escritura propiamente tal, en el sentido de una marca gráfica, esto es, quellkasca, "lo escripto, las letras. Quellcascacuna".

Cabe hacer una mención especial a un término que aparece en el Lexicón de Domingo Santo Tomás y que, evidentemente, es de origen colonial. Nos referimos a yachasca (de yachay), "ladina cosa", que amplía el campo semántico de ladino a aquel que es experimentado en aprender. ${ }^{24}$ En el mismo Lexicón aparecen las voces quillca, "letra o carta mensagera", "libro o papel generalmente"; quillcana, "escriuania”; quillcani.gui.oquillcacuni.gui, "pintar o escreuir generalmente", "labrar alguna obra con colores generalmente"; quillcacamayoc, "pintor generalmente"; quillcaqaricuni.gui, "leer letras o cartas"; quillcaqta yachac, "leydo, que lee mucho".

A la luz de este campo léxico y de la evidencia filológica que venimos rescatando, es posible reconstituir en cierta medida algunos aspectos del proceso de elaboración textual de los manuscritos señalados, proyectando la existencia de varias personas que participaban escribiendo o bien dictando a partir de la lectura de un texto, o bien dictando a "viva voz", o escribiendo, pintando (labrando, tejiendo) o dibujando. ${ }^{25}$

Las dinámicas escriturarias que hemos rescatado tanto a partir de la evidencia textual como de la lexicográfica no son privativas de este cuerpo documental (Martínez 2011, 2014). Mazzotti (1994), estudiando Suma y narración de los incas (1551) de Juan Diez de Betanzos, señala que

el problema de la pluralidad de voces en el texto se complica aún más por la misma pluralidad de las fuentes [...] Resulta difícil pensar, entonces, en la absoluta neutralidad del traductor, pues son muchas las muestras de su intervención por medio de comentarios sutilmente dosificados que no dejan de mostrar, sin embargo, una perspectiva claramente metropolitana en ejercicio oscilante ("aquí escrito"/"hablaremos") de su labor escritural (240-241).

Mazzotti propone un nuevo concepto para abordar, desde las letras, este tipo de escritura: la coralidad, como una polifonía que aparece en muchos textos andinos coloniales, entre los cuales podríamos considerar precisamente el volumen 3169, la Suma y narración, el Primer nueva corónica y buen gobierno, los Comentarios reales, etc. (Martínez 2014). Cabe poner una nota de cautela. El concepto de coralidad propuesto por Mazzotti apela a un sustrato literario de épica incaica que dialogaría con otras formas de discurso, pero en nuestro caso las formas discursivas subyacentes parecen ser de una naturaleza distinta de aquella (cuestionario, tradición oral, relación).

Finalmente, el concepto propuesto tiene completa incidencia en la metodología de trabajo filológico y hace un llamado perentorio al trabajo con las fuentes manuscritas, muchas de ellas ya en acceso digital. Gracias a este trabajo es posible estudiar las distintas etapas de gestación textual, las manos intervinientes, las variaciones lingüísticas y las posibilidades -a través de la constatación de las copias- de que existan otros manuscritos e incluso el original. Tal como lo señalara Mary Haas, "there is a tremendous amount of philological work that could be done in comparing [...] early recorded languages with their modern descendants and/ or relatives, but the surface has scarcely been scratched, largely because the philological frame of reference has been so widely neglected by American Indian linguists [...]" (Haas 1978: 187, en Cerrón 2006: 109).

\section{NOTAS}

${ }^{1}$ Este artículo es parte del proyecto FONDECYT Postdoctoral 3150110 "La formación del español andino: Parroquias de indios en los siglos XVI y XVII” y del proyecto FONDECYT Regular 1130431, ambos de la Universidad de Chile.

${ }^{2}$ Su conclusión se ha datado hacia 1608 , precisamente en la región huarochiriana, donde el cura Francisco de Ávila, autor intelectual del manuscrito, llevó a cabo una intensa campaña antiidolátrica (vid. Acosta, en Taylor 1987).

${ }^{3}$ Nos referiremos con detención a las ediciones del manuscrito más adelante en este mismo artículo.

${ }^{4}$ El mismo Francisco de Ávila, en el sermón pronunciado en 1609 en Lima en honor a Bartolomé Lobo Guerrero, señala que: "[...] ¡ cosa muy digna de risa! Cada indio, además de aquellos dioses para los que hay edificada en la aldea una morada, tiene también otro dios particular en casa y lo guarda con unos inmundísimos lienzos en medio de hojas del árbol de la coca y afirma que al ídolo le gusta comerlas, coloca también como ofrendas alimenticias otras cosas que sería largo de enumerar [...]" (en Falque 1986: 49). A lo cual añade, poco más adelante, una importante información que permite contextualizar la encuesta que daría origen al Manuscrito Huarochirí: "Prueba de ello [de los cultos idolátricos] y otras que en aras de la brevedad omito -sobre las que, como he dicho antes, intentaré publicar un libro- están tan cargadas de verdad que nos es difícil que las compruebes a través de los más fieles testimonios. Prueba de ello es el montón enorme de ídolos que yo mismo traje, de una sola parroquia, precisamente de la mía; prueba también es otro montón no menos grande que me he traído de otra. Inspecciónense los vestidos y ornamentos con los que esos ídolos eran venerados, venga el ajuar, los vasos y los morteros de los sacrificios, testifiquen [...]" (en Falque, 1986: 152, énfasis nuestro). 
${ }^{5}$ De todos los documentos, solo el Manuscrito de Huarochirí tiene rúbrica al final. Taylor (1987) se pregunta si es la rúbrica del escribano, aunque en la reedición de 2008 no se refiere al tema, a la luz de la nueva postura que adopta al proponer la autoría de Tomás.

${ }^{6}$ La numeración de las fojas que haremos a lo largo de este artículo es la del volumen 3169 completo -tal como queda consignado en los márgenes derechos de las fojas- y no la de cada documento individualmente, salvo en caso de que se señale lo contrario.

${ }^{7}$ Parece interesante señalar que en la digitalización actual que ofrece la Biblioteca Nacional de España en su página web, en el lomo del volumen se lee "MOLINA. Fábulas y ritos de los Ingas".

${ }^{8}$ La Relación de Molina se inserta además - y como lo señalamos anteriormente- dentro del contexto de las Informaciones que solicitó el virrey Francisco de Toledo cuando llegó al Perú con el objeto de legitimar el reinado español en ultramar. Molina, en este escenario, dada su experiencia lingüística y por haber acompañado en sus últimos momentos a Túpac Amaru, surgió como una persona de interés para el virrey, quien lo incorporó dentro de su agenda a tan solo un año de haber asumido el gobierno, aunque sus políticas no alcanzaron a tener incidencia en su relato.

${ }^{9}$ Así, en la copia de Molina encontramos espacios en blanco en las fojas 13r, 16r, 16v, 17v, 18v, 22r, 23r, 23v, 26r, 26v, 27r, 30r, 31r (?), 31v, 34r.

${ }^{10}$ Evidentemente, se trata del mismo volumen cuya numeración ha cambiado desde 1933, cuando Julián Paz realizó su Catálogo de manuscritos de América.

${ }^{11}$ Encontramos signos de copia en las fojas 39r, 39v, 40r, 44r, 44v, 45r, 46r, 47r, 49r, 50r, 55r, 58r, 60r.

${ }^{12}$ Es necesario, sin embargo, consignar que otros autores ya incurrieron en este error previamente. Por ejemplo, Duviols, en el estudio biográfico que hace para la edición de Arguedas, también confunde las letras (1966: 230-231).

${ }^{13}$ Agradecemos a uno de los evaluadores anónimos de este manuscrito por indicarnos que Carlos Romero y Horacio Urteaga (1916) y Laura Pujana (1999) también editaron Traslado.

${ }^{14}$ Vide s.v. trasladar. Otra de sus acepciones puede ser: "pasar algo o traducirlo de una lengua a otra" (DRAE).

15 Jorge Cabral, en 1918, reproduce íntegramente las referencias aportadas por Jiménez de la Espada. Para más referencias sobre las distintas ediciones en la primera mitad del siglo xx, véase Durston 2007.

16 "If the HM was written by a single person, it is still possible that this scribe simply produced a clean copy based on a group effort. If only out of caution, Salomon speaks of the 'makers' of the text in plural (e.g. Salomon 1991, 1). The HM could be a compilation of previous writings, and it is widely believed that it contains 'transcripts' of oral narratives provided by different informants (e.g. Arguedas 1966, 10; Salomon 1991, 31-32; Taylor 1999, xv). George Urioste envisioned a process involving multiple stages of redaction, and perhaps multiple writers, in which oral testimonies were transcribed and then had to be woven into a book-like whole, which itself may have had to be re-transcribed (Urioste 1973, 7-10). There appears to be textual evidence for the view that the $H M$ was a collaborative work involving, if not several writers, several participants whose 'voices' are present in it" (Durston 2007: 230-231).

${ }^{17}$ Durston (comunicación personal) opina que estos espacios en blanco no implican necesariamente una dificultad de lectura de la versión anterior, sino que el autor no recordaba el nombre en el momento de la escritura y lo dejó en blanco. Al conseguir el dato, posteriormente, llenó los blancos, pero Ávila no habría logrado hacer lo mismo con su versión castellana.
${ }^{18}$ Entendemos por "escribano de menudo y de mediano" a aquel escribano de calle, diferenciado del escribano de la Corona (Raïssa Kordić, comunicación personal).

${ }^{19}$ Nos parece que el término "recogido" alude a la relación con el Manuscrito de Huarochirí, nacido de varias informaciones entregadas durante una de sus visitas y que, de alguna manera, ostenta un carácter de transmisión oral (Cf. Martínez Sagredo 2011). En este documento, hasta el momento, hemos podido identificar dos manos: la principal, que escribe desde el principio hasta la foja 126r -de Ávila, según Jiménez de la Espada- y la que termina el manuscrito.

20 "Yo Don Joan de Santacruz Pachacuti Yamqui Salcamaygua, cristiano por la gracia de Dios Nuestro Senor, natural de los pueblos de Sanctiago de Hananguaygua y Huringuaiguacanchi de Orcusuyo, entre Canas y Canchis de Collasuyo, hijo legitimo de Don Diego Felipe Condorcanqui y de Dona Maria Guayrotari; nieto legitimo de Don Baltasar Cacyaquivi y de Don Francisco Yamquiguanacu, cuyas mujeres, mis aguelas, estan vivas; y lo mismo soy bisnieto de Don Gaspar Apoquivicanqui y del general Don Gaspar Apoquivicanqui y del general Don Joan Apoyngamaygua; tataranieto de Don Bernabe Apohilas Urcunipoco y de Don Gonzalo Pizarro Tintaya y de Don Carlos Huanco, todos caciques principales que fueron en la dicha prouincia y cristianos profesos en las cosas de nuestra santa fe catolica" (f. 132 r).

${ }^{21}$ En su edición de la Relación, Duviols destaca que este manuscrito está firmado por Pachacuti. Asimismo, identifica como anotaciones del extirpador "el título general "Yngas"; en la hoja que antecede a la relación de Molina, donde se lee "Chile año de 1559 fue el primer rebellón de los yndios araucanos"; en la primera página de título de "Relación" de Molina; en la primera página de título "Tratado de un cartapacio"; en la página en la que sólo aparece el título de "Relación de antigüedades dese reyno del Pirú" en la que además de este título se lee de su puño y letra "es notable" y "son quatro quadernos". Insiste Duviols en que, aunque el título de Relación... no está caligrafiado sino escrito a vuela pluma, es de su autoría" (Duviols 1993: 14).

${ }^{22}$ Navarro Gala señala que era común que los indios principales tuviesen a su servicio escribanos o secretarios e indígenas dedicados a las labores administrativas. Recordemos además que los sacerdotes solían tomar a los indígenas como ayudantes y los formaban como escribanos, ejemplo de lo cual entrega del padre Jerónimo de Mendieta: "los religiosos les ayudaron harto a salir escribanos, porque los ocupaban a la continua en escribir libros y tratados que componían o trasuntaban de latino romanza en sus lenguas de ellos" (en Navarro 2007: 16-17). Esto complejiza el panorama de la existencia de talleres de escritura donde los indígenas eran iniciados con la copia y luego adquirían mayor autonomía (al respecto, véase Martínez 2011).

23 "Explicación de la voluntad en orden a lo que se debe ejecutar, sin rescripto, bula o decreto. // Expresión oral, por contraposición a la escrita" (DRAE, s.v).

${ }^{24}$ Yachachic, "ayo, que enseña a otro", yachachini.gui, "disciplinar, o enseñar", yachachisca, "disciplinado o enseñado", "doctrinado o enseñado", yachachini, "dar lectio el maestro", yachacuni.gui, "habituarse", yachacchic, "doctor que enseña", yachacuni.gui, "deprender alguna cosa", yachasca, "abezado assi", "ducho, cosa acostumbrada", yachamuni, "decorar en la memoria” (Santo Tomás 1560: s.v.).

${ }^{25}$ Llama la atención que en los diccionarios bilingües de los siglos XVI y comienzos del XVII no existan términos como copia o traslado con el sentido que aquí referimos. Existen, sin embargo, vocablos como astani, "traslado", pero con el sentido de mover una cosa de lugar (véase s.v. Santo Tomás 1560). 


\section{REFERENCIAS}

Arguedas, J. M. (Ed)., 1966. Dioses y hombres de Huarochirí. Lima: IEP. Benozzo, F., 2010. Etnofilologia. Un 'introduzione. Napoli: Liguore.

CABRAL, J., 1918. Los cronistas e historiadores de Indias y el problema de las dinastías de la monarquía peruana. Buenos Aires: F. Álvarez \& Cía.

CERrón, R., 2006. Lingüística histórica y filología en el área andina. BIRA 33: 109-127.

Durston, A., 2007. Notes on the authorship of the Huarochirí Manuscript. Colonial Latin American Review 16 (2): 227-241.

Duviols, P., 1966. Estudio biobibliográfico. En Dioses y hombres de Huarochirí, J. M. Arguedas, Ed., pp. 218-229. Lima: IEP.

Duviols, P., 1993. Relación de antigüedades deste Reyno del Pirú. Cuzco: Travaux de l'Institut français d'études andines (74)-Centro de estudios regionales andinos Bartolomé de las Casas.

FAlque, E., 1986. El discurso de denuncia de las idolatrías de los indios, por Francisco de Ávila (1609). En Cuadernos para la Historia de la Evangelización en América Latina, H. Urbano, Ed., pp. 141-166.

Galante, I., 1942. De priscorum Huarochiriensium origine et institutis. Madrid: csic-Instituto Gonzalo Fernández de Oviedo

Hernández, F., 2010. La élite incaica y la articulación del Tahuantisuyo. Tesis para optar al grado de Doctor. Facultad de Geografía e Historia, Universidad Complutense de Madrid.

JiménEZ DE LA EsPADA, M., 1879. Tres relaciones de antigüedades peruanas. Madrid: Imprenta y Fundición Tello.

Lamana, G., 2012. Textos y actos de Polo de Ondegardo. Lima: Trabajos del IFEA.

LeÓn Llerena, L., 2007. Historia, lenguaje y narración en el Manuscrito de Huarochirí. Perspectivas Latinoamericanas 4: 54-64.
Martínez, P., 2011. Algunas reflexiones sobre las prácticas escriturarias en los Andes coloniales (siglo XVII). Atenea 503: 93-109. Concepción: Universidad de Concepción.

Martínez, P., 2014. El castellano y la castellanización de los indígenas del común en el Cuzco colonial (1532-1700): Métodos, espacios y prácticas. Tesis para optar al grado de Doctora en Literatura, Facultad de Filosofía y Humanidades, Universidad de Chile, Santiago.

Mazzotti, J., 1994. Betanzos: De la “épica” incaica a la escritura coral. Aportes para una tipología del sujeto colonial en la historiografía andina. Revista de Crítica Literaria Latinoamericana 20 (40): 239-258. Lima.

Navarro, R., 2007. Relación de antigüedades deste reyno del Pirú. Madrid-Frankfurt: Iberoamericana-Vervuert.

Pujana, L., 1999. Polo de Ondegardo: Un cronista vallisoletano en el Perú. Valladolid: Universidad de Valladolid.

Romero, C. \& H. Urteaga, 1916. Colección de Libros y Documentos referentes a la Historia del Perú, tomo III. Lima: Imprenta y Librerías San Martín.

SAlomon, F., 1991. Nueva lectura del libro de las huacas: La edición del Manuscrito de Huarochirí de Gerald Taylor (1987). Revista Andina 9 (2): 463-185. Perú: Centro Bartolomé de Las Casas.

SAnto Tomás, D. 1560. Lexicón o vocabulario de la lengua general del Perú. Valladolid: Francisco Fernandes.

TAYLOR, G., 1987. Ritos y tradiciones de Huarochirí. Lima: IEP-IFEA.

TAYlor, G., 2008. Ritos y Tradiciones de Huarochirí. Lima: IfEA-IEPUNMSM.

Urbano, H. \& P. Duviols, 1989. Fábulas y mitos de los incas. Madrid: Historia 16.

Urioste, J., 1983. Los hijos de Pariyaqaqa: La tradición oral de Waru chiri. Syracuse: Maxwell School of Citizenship and Public Affairs.

ZANELli, C., 2012. De Cajamarca a Huarina: Imágenes conflictivas de la escritura en tres textos coloniales. BIRA 33: 89-107. 